\title{
Alfred Döblin, Naturphilosoph
}

\section{Élcio Cornelsen}

\begin{abstract}
The objective of this article is to sketch an overview of the nature philosopher Alfred Döblin by interpreting his essay Das Ich über der Natur (1927). It's about a facet of the celebrated author of the novel Berlin Alexanderplats, which until the present moment received very little attention, even in Germany, and has always left the author overshadowed by his fictional works. After the World War I the period when Döblin occupied himself intensively with the philosophical questions about nature began. Some questions, like the one about the role of the human being in nature, or yet the question about the fair attitude in human kind actions, are in the center of his essays published in the 1920s. Das Ich über der Natur, published in 1927 by Fischer, is the first powerful essay by Döblin about speculations on the nature philosophy. In this essay Döblin tries to discuss some ideas like "Ur-Ich" ("original ego") and "Ur-Sinn" ("original sense") as a highly natural instance.
\end{abstract}

Keywords: Alfred Döblin; Natural Philosophy; Das Ich über der Natur; Metaphysics.

Zusammenfassung: Ziel dieses Beitrags ist, anhand der Interpretation der Schrift Das Ich über der Natur (1927) ein kleines Bild des Naturphilosophen Alfred Döblin zu skizzieren. Es geht um eine Facette des berühmten Autors des Romans Berlin Alexanderplatr, die auch in Deutschland bis jetzt sehr wenig Aufmerksamkeit erfuhr und daher immer von seinen fiktionalen Werken überschattet blieb. Nach dem Ersten Weltkrieg begann die Phase von Döblins intensivem Philosophieren über die Natur. Bestimmte Fragen, wie etwa die Frage nach der Rolle des Menschen in der Natur und die Frage nach einem gerechten Handeln stehen im Zentrum seiner naturphilosophischen Abhandlungen der zwanziger Jahre. Die Schrift Das Ich über der Natur, die 1927 im Fischer-Verlag veröffentlicht wurde, ist eben die erste ausgearbeitete Abhandlung der Döblinschen naturphilosophischen Spekulationen. Darin versucht Döblin einige Begriffe wie „Ur-Ich“ und „Ur-Sinn“ als höchste Naturinstanz zu erörtern.

Stichwörter: Alfred Döblin; Naturphilosophie; Das Ich über der Natur; Metaphysik..

Resumo: O objetivo do presente artigo é esboçar, a partir da interpretação do escrito Das Ich über der Natur (1927), uma breve imagem de Alfred Döblin enquanto filósofo da natureza. Trata-se de uma faceta do famoso autor do romance Berlin Alexanderplatr, que, até o presente momento, recebeu muito pouca atenção também na Alemanha e, em virtude disso, sempre esteve à sombra de suas obras de ficção. Após a Primeira Guerra Mundial teve início a fase em que Döblin se ocupou intensamente de questões filosóficas sobre a natureza. Determinadas questões, como, por exemplo, a questão do papel do homem na natureza, ou ainda a questão em torno de uma postura justa nas ações humanas figuram no centro de seus ensaios de filosofia da natureza escritos e publicados nos anos 20. Das Ich über der Natur, publicado em 1927 pela editora Fischer, foi o primeiro ensaio de maior fôlego em torno das especulações döblinianas orientadas pela filosofia da natureza. Nessa obra, Döblin procura discutir alguns conceitos como "Ur-Ich" ("Eu-Primevo") e "UrSinn" ("Sentido-Primevo") na qualidade de instância suprema da natureza.

Palavras-chave: Alfred Döblin; filosofia da natureza; Das Ich über der Natur, metafísica.

\footnotetext{
* Professor adjunto da Universidade Federal de Minas Gerais. cornelsen@ufmg.br
} 


\section{Dem Autor des Berlin Alexanderplatz zu Ehren}

Anlässlich des 50. Todestages Alfred Döblins am 26. Juni 2007 fragte ich mich, wie ich den Autor ehren könnte, der meine Laufbahn als Student, Forscher und Dozent immer begleitete. Wenn ich z.B. gebeten werden würde, meine Magisterarbeit Elementos do Pensamento Filosófico-Religioso de Alfred Döblin e seu reflexo no romance „Berlim Alexanderplatz" (1995) mit einem einzigen Wort zu bezeichnen, würde ich das Wort „Pionierarbeit“ auswählen.

Sie leistete gewissermaßen eine Pionierarbeit, weil es sich damals um die erste, in Brasilien niedergeschriebene und absgeschlossene Magisterarbeit über Alfred Döblin handelte, eine der Galionsfiguren der deutschen Avantgarde in der ersten Hälfte des 20. Jahrhunderts, mit dessen Namen sein Meisterwerk, der Großstadtroman Berlin Alexanderplat\%: Die Geschichte vom Franz. Biberkopf (1929), immer assoziiert wird.

Danach kam die Phase einer weiteren Forschung zu ausgewählten Werken von Alfred Döblin im Rahmen einer Promotion an der Freien Universität Berlin, dessen konkretes Ergebnis die Dissertation Gott oder Natur. "Metaphysische Unerströmungen” im Werk Alfred Döblins (1999) war.

Wenn ich nach der heutigen Bedeutung dieser beiden Foschungsarbeiten gefragt werden würde, würde ich zweideutig darauf antworten. Einerseits kann ich mit Zufriedenheit feststellen, dass sie trotz des Zeitabstands in ihren Argumentationen und Ergebnissen noch aktuell sind. Andererseits kann ich mit gewisser Enttäuschung darauf hinweisen, dass Döblin noch heute sowohl im akademischen Milieu wie auch dem Lesepublikum generell in Brasilien weitgehend unbekannt bleibt, wenn auch die Entwicklung anderer - leider weniger! - relevanter akademischer Arbeiten in Brasilien über Döblins Leben und Werk inzwischen festzustellen ist - mit verdienter Auszeichnung für die Dissertationen von Janice Belther Romanello, A poética de Alfred Döblin e a manifestação do Grotesco em „Die Ermordung einer Butterblume“ e „Berlin Alexanderplatz" (2000), und von Alceu João Gregory, O romance „O tigre azul" como forma estética do pensamento histórico de Alfred Döblin (2004), und nicht zu vergessen die auf Deutsch verfasste Dissertation von Georg Bernhard Sperber, dem ersten „Döblinisten“ in Brasilien, Wegweiser ins "Amazonas". Studien zur Rezeption und zur Textleritik der Südamerika-Trilogie Alfred Döblins, in Deutschland 1975 abgeschlossen, oder auch die Veröffentlichung von vielen Artikeln. 
Ein mit dem Autor und dessen Werk weniger vertrauter Leser könnte meinen, dass es dabei ausschließlich um einen Interessenbereich der sogenannten Germanistik geht. Jedoch würde er sich mit dieser Annahme zutiefst täuschen. Wenn es einen deutschsprachigen Autor gibt, der Zeichen von Eklektizismus und Mannigfaltigkeit in seinem Werk hinterließ, ist dieser Autor zweifellos Alfred Döblin. Seine Texte gehen von umfangreichen Romanen - durchschnittlich mit 450 Seiten, und in einigen Fällen mit über 1.000 Seiten -, über Rezensionen, Essays und Schriften zur Literaturwissenschaft hinsichtlich der Wege des Epischen Werks in den ersten Jahrzehnten des 20. Jahrhunderts, über politische Abhandlungen und Schriften zur Naturphilosophie - immer einfließend in seine fiktionalen Werke - bis hin zu den Fachtexten im Bereich der Medizin, vor allem in Bezug auf Psychiatrie und Neurologie, also Teilbereiche, in denen er von 1905 bis 1933 beruflich tätig war.

Es werden übrigens mehrere Veranstaltungen und Veröffentlichungen in diesem Jahr sowohl in Deutschland als auch im Ausland organisiert, um den Autor von Berlin Alexanderplatz anlässlich seines 50. Todestages zu ehren. Dazu zählen eine Tagung in London vom 21. bis 23. März 2007 zum Thema „Alfred Döblin (1878-1957) - Beyond The Alexanderplatz“, die Verleihung des renommierten Alfred-Döblin-Preises der Berliner Akademie der Künste am 13. Mai 2007, und das Alfred-Döblin-Kolloquium der IADG - Internationalen Alfred-Döblin-Gesellschaft - zu deren Mitgliedern ich übrigens seit 1994 gehöre , das in Emmendingen vom 27. bis 30. Juni 2007 stattfinden wird, und zwar zum Rahmenthema „'Tatsachenphantasie' - Alfred Döblins Poetik des Wissens im Kontext der Moderne“. Die Initiative der Publikationskommission der Zeitschrift Pandaemonium Germanicum, ein DöblinDossier zu veröffentlichen, zählt ebenfalls dazu.

Nach vielen Überlegungen habe ich mich schließlich dafür entschieden, Döblin anlässlich seines 50. Todestages auf eine Art und Weise zu ehren, die dazu beitragen soll, ihn in Brasilien bekannter zu machen. Deshalb werde ich in diesem Beitrag versuchen, ein kleines Bild des Naturphilosophen Alfred Döblin anhand der Interpretation seiner Schrift Das Ich über der Natur (1927) zu skizzieren, eine Facette dieses Autors, die auch in Deutschland bis jetzt sehr wenig Aufmerksamkeit verdiente und daher immer von seinen fiktionalen Werken überschattet blieb. 


\section{Döblins "Streifzüge" durch die Naturphilosophie: Das lch über der Natur (1927)}

Nach dem Ersten Weltkrieg beginnt die Phase von Döblins intensivem Philosophieren über die Natur. Bestimmte Fragen, wie etwa die Frage nach der Rolle des Menschen in der Natur und die Frage nach einem gerechten Handeln, das durch das Lernen aus der Natur erreicht würde, wurden z.B. bereits 1913 im Roman Die drei Sprünge des Wang-lun dichterisch behandelt. ${ }^{1}$ Jetzt scheint Döblin aber genauer zeigen zu wollen, was er mit solchen Fragen in engerem Sinne meint.

Die Erlebnisse im Ersten Weltkrieg scheinen der entscheidende Faktor gewesen zu sein, der Döblin zur Auslösung seiner naturphilosophischen Spekulationen führte. ${ }^{2}$ Denn sie bewirkten in Döblin eine Skepsis gegenüber dem technischen Fortschritt, der im Dienst von Großmächten militärisch missbraucht wurde und sich in den Materialschlachten widerspiegelte. Darüber hinaus geht es in den naturphilosophischen Schriften nicht nur um Döblins Ziel, eine bessere Befriedigung der philosophischen und religiösen Bedürfnisse als die christliche Weltanschauung anbietet, $\mathrm{zu}$ finden, sondern auch um eine Warnung vor der Gefahr, die die falsche Position des Menschen zur Natur mit sich bringen würde.

Die Schrift Das Ich über der Natur, die 1927 im Fischer-Verlag veröffentlicht wurde, ist die erste ausgearbeitete Abhandlung der Döblinschen naturphilosophischen Spekulationen der zwanziger Jahre und zählt zu den Werken, die bis jetzt am wenigsten rezipiert worden sind. Sie ist zwischen 1921 und 1927 entstanden und ist aus den naturphilosophischen Essays „Buddho und die Natur“ (1921), „, „Das Wasser“ (1922) 4 und „Die Natur und ihre Seelen“ (1922) ${ }^{5}$ hervorgegangen.

Außerdem ist Das Ich über der Natur mit den Romanen der Schaffensphase zwischen 1912 und 1929, von den Drei Sprüngen des Wang-lun (1912/13) bis zum Großstadtroman Berlin Alexanderplatz (1927/29), eng verbunden. In den zeitgenössischen Rezensionen zu Das Ich über der Natur herrscht eine Tendenz, in der Döblins naturphilosophische Aussagen in

\footnotetext{
${ }^{1}$ Vgl. DöBlin 1989: 80-81; dazu vgl. CORNELSEN 1999: 32.

2 Döblin meldete sich Ende 1914 der Ober- und Reservekommission des Bezirks Berlin zum ärztlichen Militärdienst als Freiwilliger. Er diente als Militärarzt im Lazarett der Infanteriekaserne in Saargemünd; vgl. SCHRÖTER 1988: 66.

3 Vgl. DÖBLIN 1922a: 5-14; dazu vgl. CORNELSEN 1999: 215-235.

4 Vgl. DöBlin 1921: 1192-1200; dazu vgl. CORNELSEN 1999: 54-61.

5 Vgl. DÖBLIN 1922b: 853-858.
} 
Zusammenhang mit den Romanen Berge Meere und Giganten (1924) und Manas (1926) gestellt werden. In einer Rezension, die damals in der Zeitschrift Die literarische Welt erschienen ist, behauptet Axel Eggebrecht, Das Ich über der Natur sei bloß „ein Nebenwerk“, „eine Nachlese und Erläuterung“ (EGGEBRECHT 1973: 196) von beiden Romanen. Für ihn liege der Unterschied zwischen den Romanen und der naturphilosophischen Schrift darin, dass ,auf gegensätzliche Art dort die große Natur, hier der größere Mensch als siegreich dargestellt werden.“ (EGGEBRECHT 1973: 196). Eine solche Behauptung erachte ich als bedenkenswert, denn weder in den Romanen noch in der naturphilosophischen Schrift geht es um einen „Sieg““ der Natur oder des Menschen. In beiden wird der Mensch zum aktiven Handeln aufgerufen. Dieses Handeln muss zuletzt aber einem bestimmten ethischen Verhalten entsprechen: kein schrankenloses Handeln in prometheischem Sinne, sondern ein Handeln in der und durch die Natur. In derselben Richtungslinie kritisiert Hans Ehrenberg das naturphilosophische Werk Döblins. Für ihn geht es darin um die „Beherrschung der Erde“ (EHRENBERG 1973: 200). Er lehnt Das Ich über der Natur als „unnötig“ ab, weil Döblin schon vorher in Werken wie Berge Meere und Giganten und Manas alles „deutlich und viel überzeugender“" (EHRENBERG 1973: 201) verhandelt habe. Er nennt Döblin „Idealist, ein[en] Urichanbeter“ und „ein[en] idealistische[n] Materialist[en]“ (EHRENBERG 1973: 201). Für ihn ist Döblin „ein eigener Prediger in der Wüste“ (EHRENBERG 1973: 204), und sein Werk „furchtbar“ (EHRENBERG 1973: 203). Anhand dieses Beispiels kann man sich vorstellen, was für ein Aufsehen Das Ich über der Natur zur Zeit seiner Veröffentlichung erregte. Denn Döblin geht darin sehr weit, indem er sich erstmals nicht damit begnügt, die jüdisch-christliche Gottesauffassung abzulehnen, wie etwa in den Aufsätzen „Jenseits von Gott“ (1919), „Buddho und die Natur“ (1921) und „Der Geist des naturalistischen Zeitalters“ (1924) der Fall ist, ${ }^{6}$ sondern weil er unbedingt einen selbst gebastelten „Ersatz“ für Gott in der Form einer höchsten Instanz in der Gesamtnatur auf programmatische Weise anbieten will.

Einige Gedanken, die das Fundament von Döblins unsystematischem naturphilosophischem Denkgebäude bilden, stammen aus anderen Schriften der zwanziger Jahre: u.a. das „Anonyme“, die Allbeseeltheit der Natur, das Verhältnis von Organischem und Anorganischem in der Natur als Teil einer

\footnotetext{
${ }^{6}$ Vgl. DöBlin 1985, S.246-247 bzw. CoRNeisen 1999: 3; dazu vgl. DöBlin 1921: 1192 und DöBLIN 1924: 1276 bzw. CORNELSEN 1999: 55 und 243.
} 
alles umfassenden organischen Struktur. Mit Das Ich über der Natur tritt aber ein entscheidender Faktor auf: das „Ur-Ich“, auch „Ursinn“ genannt.

Wenn es um den Gebrauch von „Ur“-Termini bei Döblin in den zwanziger Jahren geht, die auch nach Döblins Bekehrung zum Katholizismus ihre Funktion - zwar inhaltlich modifiziert - beibehalten, dann kann man in der Forschungsliteratur folgende Tendenz feststellen: Die Interpreten weisen zwar meistens zutreffend auf die Bedeutung einzelner „Ur“-Begriffe hin, aber man fragt nicht nach dem Grund ihrer Anhäufung. Monique von Weyembergh-Boussart erkennt z.B., dass das „Ur“-Vokabular sich mit Döblins Idee einer „Ganzheit geistiger Art“ in der Natur verbindet (WEYEMBERGH-BOUSSART 1970: 144). Ursula Elm spricht in derselben Richtung vom „Ur-Sinn“ und vom „Ur-Ich“ als „ein[em] einheitsstifende[n] Prinzip“, welches „die Ordnung in der Natur" garantiert (ELM 1991: 39). Ein ähnliches Beispiel liefert Otto Klein, indem er den „Ur-Sinn“ als „Inbegriff des Zusammenhangs aller Dinge“ richtig interpretiert (KLEIN 1995: 44). Schließlich weist Ulrich Dronske zutreffend darauf hin, dass der „Ur-Sinn kein genetisches Prinzip, von dem die Welt ihre Existenz herschreibt“ (DrONSKE 1998: 50), enthält, d.h. er soll nicht im Sinne eines geschichtlichen Ursprungs verstanden werden. Deshalb beabsichtige ich, meinen Beitrag zu diesem Thema anders zu gestalten als die bisherige Sekundärliteratur.

Die Anhäufung vom „Ur“-Vokabular als Begrifflichkeit der Naturwissenschaft, Philosophie und Literatur tritt erstmals deutlich in der zweiten Hälfte des 18. Jahrhunderts auf. Symptomatisch dafür ist in erster Linie die Ablehnung ,der naturwissenschaftlichen Entgöttlichung der Natur durch die Aufklärung“، (KÜNG 1995: 163):

[...] der im letzten drittel des 18. jhs. immer häufiger werdende gebrauch des präfixes [ur-] hängt mit dem umschwung des geistigen lebens zusammen, das über die platte erfahrung der aufklärungsbildung hinaus zu den ursprünglichen quellen des lebens zu gelangen sucht. dann werden diese zusammensetzungen häufig: uranfang, -anlage, -atom, -aufführung, -beginn, -bestand, -form, -geschichte, -grund, -keim, -kraft, -licht, -nacht, offenbarung, -quell, -stifter, -stoff, -typus, -vergangenheit, -wahrheit, -zelle, zustand; [...] (GRIMM \& GRIMM 1936: 2358)

Was hier als „die platte erfahrung der aufklärungsbildung“ Erwähnung findet, bedarf einer genauen Erklärung. Einerseits bekämpft die Aufklärung jede metaphysische Spekulation, andererseits setzt sie den Rationalismus als Denkweise absolut: 


\section{CORNELESEN, E. - Alfred Döblin, Naturphilosoph}

[...] Der Rationalismus räumt der Ratio eine unbeschränkte Herrschaft ein, gegen die an keine höhere Instanz appelliert werden kann. Für Metaphysik ist im System des Rationalismus kein Raum. Die Geschichte der Philosophie verzeichnet deshalb einen Niedergang der Metaphysik während der Vorherrschaft des Rationalismus. [...] (SCHMIDT 1991: 569)

Somit sind die Vertreter der Aufklärung davon überzeugt, dass ,aus reinen Prinzipien des Denkens de[r] Aufbau der Wirklichkeit“ (KUNZMANN 1998: 103) erkannt werden kann. Dazu sollen sie induktiv verfahren und die Methode der Mathematik als Vorbild gebrauchen (vgl. KunZMANN 1998: 103). Darüber hinaus wird die Natur zum bloßen Objekt naturwissenschaftlicher Betrachtung.

Der mathematische Rationalismus ist nicht nur allein der Grund dafür, warum die Aufklärung in Deutschland in Misskredit geraten ist. Die Französische Revolution, deren Wurzeln in der Aufklärung liegen, verliert viele Sympathisanten in Deutschland, da sie später in jakobinischen Terror umschlägt:

Die meisten führenden Köpfe auch in Deutschland hatten sich für die Aufklärung und die „Französische Revolution“ zunächst sehr begeistert: nicht nur Kant, Jakobi, Fichte, sondern auch Klopstock, Herder, Wieland, Novalis, Friedrich Schlegel; Schiller war sogar die Ehrenbürgerwürde der Stadt Paris angetragen worden. Aber gerade gegen Ende von Hegels Tübinger Zeit hatte in Paris die revolutionäre Diktatur der Jakobiner eingesetzt: Schon die Septembermorde 1792 hatten die Sympathie für die Revolution im Ausland stark abgekühlt. Im Januar 1793 war Ludwig XVI. hingerichtet worden. Es begann die furchtbare Zeit des Wohlfahrtsausschusses unter Robespierre mit den in die Tausende gehenden Massenexekutionen. [...] Wie Herder, Schiller, Klopstock und andere, so verurteilen jetzt auch Hegel, Schelling und Hölderlin den jakobinischen Terror, ohne indessen die Ziele der Revolution aufzugeben. (KÜNG 1995: 158-159) ${ }^{7}$

Ein weiterer Grund - und wahrscheinlich der entscheidende - für die Suche nach anderen Wegen als dem der Aufklärung ist die vorherrschende mechanistische Erklärung der Natur unter den Aufklärern, die entweder im philosophischen Deismus - z.B. bei Voltaire ${ }^{8}$ - oder im materialistischen Atheismus - z.B. bei Holbach und Lamettrie ${ }^{9}-$

\footnotetext{
${ }^{7}$ Dazu vgl. KunZMAnN 1998: 135.

${ }^{8}$ Voltaire (1694-1778) gilt als Vorkämpfer des Deismus (Lateinisch: „,deus“, „Gott“) in Frankreich, der seine Wurzeln in der englischen Aufklärung bei Herbert von Cherbury (1583-1648) hat. Voltaire lehnte die Offenbarungsreligionen $\mathrm{ab}$ und entwickelte dagegen eine eigene Weltsicht, über die er unter dem Einfluss Isaak Newtons (1643-1727) die Natur als mechanische Gesetzlichkeit auffasst und sie nach Descartes rationalistisch verabsolutiert; vgl. HÖFER \& RAHNER 1959: 197-198.

${ }^{9}$ Vor allem Dietrich von Holbach (1723-1789) und Julien Offray de Lamettrie (1709-1751) vertraten in der Aufklärung einen materialistischen Monismus, in dem nur die Existenz der Materie für wahr angenommen
} 


\section{CORNELESEN, E. - Alfred Döblin, Naturphilosoph}

mündet. ${ }^{10}$ Als Folge des Atheismus der Aufklärung setzt sich dann der Trend der Aufhebung der metaphysischen Einheit der Natur durch. Die Gegner der Aufklärung suchen hingegen die Idee der Ganzheit der Natur zu retten, in der sich Göttliches offenbart. Infolgedessen greifen sie die Möglichkeit auf, das mechanistische Paradigma durch das organistischpantheistische Paradigma ${ }^{11} \mathrm{zu}$ überwinden, um die Natur wieder zu „vergöttlichen“:

[...] Ja, der naturwissenschaftlichen Entgöttlichung der Natur durch die Aufklärung folgte Herders, Goethes und Hölderlins Wiedervergöttlichung der Natur. Philosophisch hat sie sich vor allem in Schellings frühen Werken Ausdruck verschafft: Der Sinn für die lebendige, umfassende Totalität alles Seienden setzte sich durch, der Sinn für die als Leben verstandene Natur, für das als göttlich verstandene Leben. (KÜNG 1995: 163)

In Bezug auf Döblins Gebrauch des „Ur“-Vokabulars sind Goethe und Hölderlin ${ }^{12}$ sicher zwei Vorbilder für ein solches sprachliches Verfahren. Ähnlich wie Döblin setzen Goethe und Hölderlin bestimmte Begriffe mit dem Präfix „Ur“- des öfteren zusammen, um einen sprachlichen Effekt zu erzielen, der die Totalitätsidee in den verschiedensten Lebensbereichen widerspiegeln soll. Obwohl Döblin sich über Goethe nicht immer positiv

wird, während jedes metaphysische Argument zugunsten eines selbständigen geistigen Prinzips hinter der Materie für sie „Täuschung, Irrtum, Hirngespinst“" sowie die Religion „Täuschung, und zwar bewußte, absichtliche Täuschung: Priestererfindung, Priesterbetrug" bedeutet; STÖRIG 1995: 375.

${ }^{10}$ Vgl. STÖRIG 1995: 570-571; dazu vgl. ZAHN 1989: 67 bzw. CORNELSEN 1999: 216.

11 Die pantheisierende Grundhaltung, die sich seit Ende des 18. Jahrhunderts in Deutschland durchgesetzt hat, wurde vorwiegend durch die Auseinandersetzung mit Spinozas Pantheismus ermöglicht. Goethe rezipierte z.B. den „Spinozismus“ nicht direkt, d.h. obwohl er sich mit Spinozas Schriften um 1784 beschäftigte, wurde für ihn Spinozas Lehre vielmehr präsent durch die Diskussion mit Herder und Jacobi über deren Sicht des „Spinozismus“; zu Goethes Spinozarezeption vgl. GrunwaLd 1986: 117-126. Ähnlich diskutierte auch Hölderlin Spinozas Pantheismus im Anschluss an Jakobis „Briefen über die Lehre des Spinoza“; vgl. HÖLDERLIN 1961a: 207-210. Ein weiteres Beispiel für die Rezeption Spinozas um 1800 liefert Novalis. In einem Fragment drückt er kurz sein Verständnis vom „Spinozismus“ aus: „Der Spinozism ist eine Übersättigung mit Gottheit. Unglauben und ein Mangel an göttlichem Organ und an Gottheit. Es gibt also direkte und indirekte Atheisten. Je besonnener und echt poetischer der Mensch ist, desto gestalteter und historischer wird seine Religion sein“; HARDENBERG 1929a: 551.

12 In Döblins Augen sind Goethe und Hölderlin - neben Marx und Nietzsche - Beispiele für die adäquate Menschenhaltung gegenüber der Natur im „,naturalistischen Zeitalter“, die im Gegensatz zur durch den Klerikalismus vermittelten Haltung steht:

Welche, ist umgekehrt, die Wirkung der Menschheitsideen auf das Dasein innerhalb der naturalistischen Epoche? Ein ungeheures Gebiet! Man hat bisher die großen Ideen zu einer Naturverachtung benutzt, die bis zu einer Mönchshaltung gegen die Welt führte. Mönchshaltung, buddhistischer Augenschluß war die Konsequenz der Ideen! Das ist ein Überbleibsel aus der dualistischen Periode: Natur contra Geist, natürlicher Mensch contra religiöser Mensch. Jetzt - ist nur ein Mensch da, der natürliche, - er hat die ungeteilte geistige Natur. Sein Bewußtsein ist aber heute noch nicht zur Anerkenntnis dieser Natur vorgedrungen; der Mensch lebt sich noch nicht, er wird gelebt und duldet viel: Nachwirkung der alten Geisteshaltung!

Es heißt jetzt Erkenntnis der Natur und des menschlichen Daseins! Die Namen Goethe, Hölderlin, Nietzsche, Marx, leuchten als die ersten Sterne. (DÖBLIN 1972c: 243-244). 
geäußert hat, erkennt er besonders die hervorragenden Beiträge Goethes im Rahmen seiner Naturlehre an:

Mit Ehrfurcht denke ich an den Mann, den ich viel angegriffen habe, ich wie viele andere, und von dem ich jetzt und noch oft reden werde, weil er mir oft gegenwärtig ist, nämlich Goethe. Ich habe ihn so wenig gekannt wie die Millionen anderer, die ihn verehren. Ich habe ihn dann geschmäht, weil ich ehrlich bin und er zu dem Lehrplan und Lernstoff gehörte. Und nun schwimme ich langsam in seinem Wasser. Dieser Mann steht in vielen großen Städten auf marmornen Sockeln, man hat ihn so hoch setzen müssen, um zu zeigen, wie weit man sich von ihm entfernte. Es ist nötig, ihn herunterzuholen. Eingehen in ihn kann man durch seine Farbenlehre, die Pflanzenmetamorphose, Gespräche, Briefe. [...] (DÖBLIN 1972a: 54-55).

Die naturwissenschaftlichen Beiträge Zur Farbenlehre (1810) und Zur Morphologie (1824) sind eben diejenigen Werke, in denen Goethe „Ur“-Begriffe besonders prägt und sie häufig gebraucht. Goethe, der ,davon überzeugt war, dass die ganze erschaffene Welt harmonisch ist“ (HENEL 1980: 160), sieht die Abstraktionen der mathematischen Physik der Aufklärung als „bloße Hirngespinste“ (HENEL 1980: 176). In seiner kritischen Sicht zerstört die mathematische Physik die Totalität der Naturphänomene, die von den Sinnen wahrgenommen werden, ohne sie wiederherzustellen (vgl. HENEL 1980: 178). Deshalb versteht Goethe die Verfahrensweise der experimentellen Wissenschaft nur als eine der Möglichkeiten, die Natur zu erforschen. Er selbst will aber weder den Weg der romantischen Naturphilosophie einschlagen, da sie in seinem Verständnis „ein bloßes Produkt des Geistes“ (HENEL 1980: 178) sei, noch den Weg der rein wissenschaftlichen Empirie. Statt dessen wählt er den dritten Weg: die alltägliche Erfahrung des Beobachtens der sinnlich wahrnehmbaren Natur (vgl. HeNEL 1980: 167). Als Resultat seiner unzähligen Naturbeobachtungen prägt Goethe dann Begriffe wie „Urpflanze“, „Urtier“ und „Urphänomen“:

[...] über die naturwissenschaftliche terminologie, der urchamäleon (farbe), urdetermination, -farbe, -granit, -gestirn, -glieder, -grünstein, körper, -lage, -metall, -polarität, -sandstein, -schall, -theilchen, -wirbel u.a. angehören, geht $G$ [oethe] mit individuellen bildungen weit hinaus. die „urpflanze“ als ursprüngliches, einfachstes gedachtes modell, als morphologischer typus der ganzen pflanzenwelt, sowie das „urphänomen“, ein letztes, unerforschliches, ursprüngliches, nur der idee und der inneren anschauung zugänglich [...] sind sein eigenthum. wie die „urpflanze“ sucht er das „urthier“. [...] (GRIMM \& GRIMM 1936: 2358). 


\section{CORNELESEN, E. - Alfred Döblin, Naturphilosoph}

In seiner naturwissenschaftlichen Schrift Zur Farbenlebre schreibt Goethe z.B.:

[...] Wir nennen sie [d.h. Phänomene] Urphänomene, weil nichts in der Erscheinung über ihnen liegt, sie aber dagegen völlig geeignet sind, daß man stufenweise, wie wir vorhin hinaufgestiegen, von ihnen herab bis zu dem gemeinsten Falle der täglichen Erfahrung niedersteigen kann. [...] (GOETHE 1890: 72) (vom Verfasser unterstrichen).

So unterscheidet Goethe durch die Bildung vom „Ur“-Vokabular das Wort „Urphänomen“ graduell von „Phänomen“. Hinter diesem „wissenschaftlichen Konstrukt“ (DAHNKE \& OTTO 1998: 1080) steckt die Absicht, das „Urphänomen“ als ein umfassendes „Phänomen“ zu definieren, welches, wie Heinrich Henel zutreffend erläutert, sowohl einfach und den wenigsten Bedingungen unterworfen ist, als auch „ein Gesetz zu erkennen gibt, das ein ganzes Gebiet der Natur beherrscht“ (HENEL 1980: 165). ${ }^{13}$

Eine weitere Motivation für Döblins Gebrauch vom „Ur“-Vokabular kann sicher bei Friedrich Hölderlin (1770-1843) gefunden werden. Neben Spinoza spielt Hölderlin in Döblins Gymnasialzeit eine markante Rolle. Nach eigener Auskunft trug er Hölderlins Hyperion jahrelang in seiner Brusttasche, „bis das Heft nur noch aus losen Blättern bestand“ (DÖBLIN 1986: 194). In einer Theaterkritik zur Aufführung vom Drama Der Tod des Empedokles (1800) bezeichnet er Hölderlin wegen seiner anscheinend pantheisierender Haltung als einen „Naturvergötterer“ (DÖBLIN 1990: 278). Tatsache ist, dass der Briefroman Hyperion oder Der Eremit in Griechenland (1797/1799) auch Passagen beinhaltet, in denen Hölderlin Gebrauch vom „Ur“-Vokabular macht, wie z.B.:

Oft treten Erscheinungen vor unsre Sinne, wo es uns ist, als wäre das Göttlichste in uns sichtbar geworden, Symbole des Heiligen und Unvergänglichen in uns. Oft offenbart sich im Kleinsten das Größte.

Das Urbild aller Einzigkeit, das wir im Geiste bewahren, es scheint uns wieder in den friedlichen Bewegungen unsres Herzens, es stellt sich im Angesichte dieses Kindes dar.

(HÖLDERLIN 1946d: 190) (vom Verfasser unterstrichen)

Der Mensch kann es nicht verläugnen, daß er einst glücklich war, wie die Hirsche des Forsts und nach unzähligen Jahren klimmt noch in uns ein Sehnen nach den Tagen der Urwelt, wo jeder die Erde durchstreifte, wie ein Gott, eh, ich weiß nicht was? Den Menschen zahm gemacht, und noch, statt Mauern und todtem Holz, die Seele der Welt, die

\footnotetext{
${ }^{13}$ Zur Interpretation von Goethes Begriff des „Urphänomens“ vgl. auch DAHNKE \& OTTO 1998: 1080 bzw. PIZER 1989: 205-222.
} 


\section{CORNELESEN, E. - Alfred Döblin, Naturphilosoph}

heilige Luft allgegenwärtig ihn umfieng. (HÖLDERLIN 1946c: 112) (vom

Verfasser unterstrichen)

Die Zusammensetzung des Präfixes „Ur“- mit dem Wort „Bild“ tritt in der deutschen Sprache erstmals im 17. Jahrhundert auf. Ursprünglich steht „Urbild“ für Archetypus, im 18. Jahrhundert dann für „original“ und „ideal“ (vgl. GrIMM \& GRIMM 1936: 2385). „Urwelt“ datiert auch aus dem 17. Jahrhundert. Wie das „Urbild“ konnotiert der Begriff der „Urwelt“ die Idee vom ursprünglichen, idealen Weltzustand (GRIMM \& GRIMM 1936: 2606). Ihrer Bedeutung im 18. Jahrhundert gemäß drücken „Urbild“ und „Urwelt“ in beiden Passagen des Hyperion die Idee eines ,goldenen Zeitalters“ des harmonischen Verhältnisses von Gott, Mensch und Natur aus, welches das klassische Idealbild des alten Griechenlands repräsentiert. ${ }^{14}$ Der religiöse Charakter des „Urbilds“ und der „Urwelt“ bei Hölderlin wird durch die Attribute „,heilig“, „,allgegenwärtig“ und „,unvergänglich“ hervorgehoben. ${ }^{15}$

Als letztes Beispiel für die Anhäufung vom „Ur“-Vokabular in der zweiten Hälfte des 18. Jahrhunderts muss Novalis (eigentlich Friedrich Leopold Freiherr von Hardenberg) (1772-1800) angeführt werden. Obwohl es keinen Beleg für einen direkten Einfluss Novalis' auf Döblins literarisches Schaffen gibt, ist es dennoch unstrittig, dass es doch eine gewisse geistige Verwandtschaft zwischen beiden gibt, wenn es um das Verhältnis von Wissenschaft, Kunst und Philosophie geht. Anders als Goethe, geht Novalis bei seiner Naturbetrachtung weder von einer sinnlichen Naturerfahrung, noch von einem intuitiven Gefühl für die Natur aus (vgl. NeUbAUER 1997: 52). Statt dessen beruht seine Naturbetrachtung auf einer naturphilosophischen

\footnotetext{
14 Weitere Beispiele für die Anhäufung vom „Ur“-Vokabular bei Hölderlins Werk findet man u.a. in den Gedichten „Emilie vor ihrem Brauttag“ („Urbild“; vgl. HöLDERLIN 1946a: 291), „Hymne an die Schönheit“ („Urgestalt“; vgl. HÖLDERLIN 1946b: 149), „Die Unsterblichkeit der Seele“ („Urstoff“; vgl. HÖLDERLIN 1946f: 24), „Wenn aus der Ferne...“ („Urwelt“; vgl. HöLDERLIN 1946g: 262) und „Kanton Schweiz. An meinen Lieben Hiller“" („Urzeit“; vgl. HÖLDERLIN 1946e: 143).

15 Weyembergh-Boussarts Interpretation der möglichen geistigen Verwandtschaft zwischen Hölderlin und Döblin erweist sich als bedenklich. Denn was als „,religiös“ bei Hölderlin vorkommt, gewinnt bei Döblin eine andere Qualität, indem er dies mit physikalisch-chemischen Aspekten verbindet. Aus diesem Grund bin ich der Meinung, dass „das schöpferische Walten eines Allgeistes“, das Hölderlin nach Weyembergh-Boussarts Sicht annahm, mit dem „Geistigen“ und der „Seele“ bei Döblin, von der verschiedenen Bedeutung her, außer der metaphysischen Totalitätsidee kaum etwas gemeinsam hat; vgl. WEYEMBERGH-BOUSSART 1970: 149. Diese Totalitätsidee beinhaltet bei Hölderlin, wie bei Döblin, eine dynamische Auffassung des Lebens als Werden und Vergehen:

[...] Der Moment, wo die Periode des individuellen sich endet, ist da, wo das Unendlichneue als auflösende, als unbekannte Macht, zum individuellalten sich verhält, eben so wie in der vorigen Periode das neue, sich als unbekannte Macht zum unendlichalten verhalten, und diese zwei Perioden sind sich entgegengesetzt, und zwar die erste als Herrschaft des individuellen über das Unendliche, des einzelnen über das Ganze, der zweiten als der Herrschaft des Unendlichen über das Individuelle, des Ganzen über das Einzelne. Das Ende dieser zweiten Periode und der Anfang der dritten liegt in dem Moment, wo das Unendlichneue als Lebensgefühl (als Ich) sich zum individuellalten als Gegenstand (als Nichtich) verhält, [...]; HÖLDERLIN 1961b: 286-287.
} 
Denkweise, die besonders unter dem Einfluss Fichtes und Schellings steht (RODER 1992: 523) und die Idee einer natürlichen und geistigen Entwicklung in einem gesamten, organischen Weltbild als ihren Kern hat:

Gesellschaftstrieb ist Organisationstrieb. Durch diese geistige Assimilation entsteht oft aus gemeinen Bestandteilen eine gute Gesellschaft um einen geistvollen Menschen her. (HARDENBERG 1929a: 471)

Der Weltstaat ist der Körper, den die schöne Welt, die gesellige Welt, beseelt. Er ist ihr notwendiges Organ. (HARDENBERG 1929a: 487-488)

Die Ähnlichkeit solcher Fragmente mit Döblins Aussagen im Aufsatz „Der Geist des naturalistischen Zeitalters“ ist auffällig. Novalis' Hinweis auf die organische Struktur des Lebens ist übrigens konform mit der allgemeinen Zeitströmung. Denn statt einer mechanischen Naturordnung, wie die Aufklärer betonen, in der das Kausalitätsprinzip herrscht, vertritt z.B. der deutsche Idealismus die Idee eines lebendigen, unauflöslichen Zusammenhangs zwischen allen einzelnen Organen, die den ganzen Organismus komponieren (vgl. RODER 1992: 318-319).

In Novalis' Werk Heinrich von Ofterdingen (1800) spielt ein Begriff, der nach dem Verfahren der Zusammensetzung von „Ur“" mit Begriffen gebildet wird, eine zentrale Rolle: die „Urzeit“. Die Zusammensetzung vom Präfix „Ur" - mit „Zeit“ stammt aus dem 17. Jahrhundert. Wie die meisten „Ur“Begriffe, wurde „Urzeit“ erst im letzten Drittel des 18. Jahrhunderts häufiger gebraucht (vgl. GRIMM \& GRIMM 1936: 2612). Im weiteren Sinne bedeutet „Urzeit“ ursprünglich sowohl einen ,zeitraum der vorgeschichte, etwa bis zur ältesten steinzeit", als auch ,älteste geschichte schlechthin“ (GRIMM \& GRIMM 1936: 2613). Wie Wilhelm Emrich mit Recht behauptet, setzt das geschichtliche Denken der Romantik eine „Metaphysik der Urzeit, der goldenen Zeit“ (EMrich 1942: 278) voraus. Durch die Symbolik der „goldenen Zeit", die der Begriff der „Urzeit“ in sich einschließt, wird eine metaphysische Idee von „Totalität und Universalität“ (EMRICH 1942: 284) vermittelt, in der sich „eine[...] ideale [...] gesetzmäßige [...] Ganzheit“ (EMRICH 1942: 279) widerspiegelt. So ist die ,goldene Zeit“ in der Auffassung der Romantik geschichtlich nicht lokalisierbar, d.h. sie ist kein Symbol für irgendeine geschichtliche Frühzeit (vgl. EMRICH 1942: 279). ${ }^{16}$ Laut Wilhelm Emrich zielten die Romantiker mit ihrem Begriff der „Urzeit“ darauf, einem Idealbild deutlich Konturen zu verleihen, indem es in eine ferne und ideale Zeit verlagert wird:

\footnotetext{
${ }^{16}$ Dazu vgl. HASLINGER 1981: 167.
} 


\section{CORNELESEN, E. - Alfred Döblin, Naturphilosoph}

Das Rückgreifen der Romantik auf eine Urzeit als Ausgangspunkt geschichtlicher Deutungen hat aber noch einen anderen, tief geschichtsmethodischen Hintergrund: Die Reinheit überpersönlicher, geschichtlicher Gesetze, die im subjektiv verengten Blickpunkt der Gegenwart verfehlt, gestört, abgelenkt oder überhaupt geleugnet schienen, dringt aus einer entrückten Vorzeit deutlich hervor, [...] (EMRICH 1942: 278179).

In Bezug auf Novalis’ Gebrauch des Begriffs der „Urzeit“ erweist sich Emrichs Definition als zutreffend. Novalis entwickelt den Begriff der „Urzeit“" vorwiegend im Sinne einer idealisierten, fiktiven Zeit, in der die Einheit der Natur noch bestand. Zum Beispiel realisiert in der folgenden Passage von Heinrich von Ofterdingen der Protagonist im Traum die Wiederherstellung der verschollenen Einheit der Natur:

[...] Selbst wie ein Traum der Sonne, lag er [d.h. Heinrich] über der in sich gekehrten Traumwelt, und führte die in unzählige Grenzen geteilte Natur in jene fabelhafte Urzeit zurück, wo jeder Keim noch für sich schlummert, und einsam und unberührt sich vergeblich sehnte, die dunkle Fülle seines unermeßlichen Daseins zu entfalten. [...] (HARDENBERG 1929b: 156) ${ }^{17}$ (vom Verfasser unterstrichen)

Bis hierher konnte man deutlich feststellen, dass die Art und Weise, wie manche deutsche Dichter seit dem letzten Drittel des 18. Jahrhunderts eine Antwort auf den rationalistischen Materialismus der Aufklärung gaben, ihre Folgen auch im Bereich der Sprache hat. Nach der „Urzeit““ und der „Urwelt“ zu fragen, oder noch vom „Urbild“, „Urpflanze“ und „Urphänomen“ zu sprechen, sind nichts Weiteres als Versuche, die von der Aufklärung bekämpfte Metaphysik ${ }^{18}$ sprachlich wieder auf die Tagesordnung zu bringen. Die Hinwendung zur Metaphysik ist eben das gemeinsame Phänomen, das die Epoche um 1800 mit der Wende zum 20. Jahrhundert trotz aller Vorbehalte verbindet. Gewiss steckte die „Verquickung von technisch-industriellem Fortschritt und wissenschaftlicher Bestrebung“, wie Florian Roder es richtig sieht, „damals erst in den Anfängen“ (RODER 1992: 523). Infolgedessen war es trotzdem noch möglich, dass „neben

\footnotetext{
${ }^{17}$ Dazu vgl. auch Hardenberg 1929b: 162 bzw. 165. Außer dem Begriff der „Urzeit“ findet man in Novalis” Werk auch den Begriff der „Urwelt“, der, wie bei Hölderlin, in Zusammenhang mit dem idealen Bild der „goldenen Zeit“ steht; vgl. HADERNBERG 1929b: 236, 244 bzw. 259 und HARDENBERG 1929c: 352.

18 Die Metaphysik (Griechisch: „meta ta physika“, „nach bzw. hinter dem Physischen“), von Aristoteles ausgehend, umfasst vier verschiedene Lehrbereiche: die Lehre vom Seienden (Ontologie); die Lehre vom göttlichen Sein (philosophische Theologie); die Lehre von der Seele (Psychologie); schließlich die Lehre vom Wesen der Welt hinsichtlich des Zusammenhangs alles Seienden im Ganzen (Kosmologie). Die Metaphysik hat als ihre Gegenstände u.a. Sein, Unsterblichkeit, Gott, Natur, Leben, Materie, Seele und Geist; vgl. SCHMIDT 1991: 452 bzw. KUNZMANN 1998: 13.
} 
materialistische[n] Erklärungsversuche[n]“ „ein ganzheitliche[s], die zerstreuten Erscheinungen umfassende[s] Naturverstehen idealistischer Art“ (RoDER 1992: 523) seine Gültigkeit noch finden konnte. Hinzu kommt, dass trotz der Religionskritik der Aufklärung das christliche Weltbild nicht so diskreditiert wurde, wie dies später der Fall ist. Denn vor allem Darwins Deszendenztheorie, Marx' Religionskritik sowie Nietzsches und Freuds Kritik am Gottesglauben sind entscheidende Momente, die in der Zeitspanne zwischen beiden Epochen liegen und der Hinwendung zur Metaphysik um 1900 andere Konturen verleihen. ${ }^{19}$ Aber was damals als metaphysischeEinheit im Göttlichen verstanden wurde, tritt um die Jahrhundertwende als metaphysische Einheit des Lebens auf. Man lehnt daher den Gottesbegriff ab, aber die Idee der Einheit wird doch bewahrt. Dieselben Grundlagen z.B. der Romantik und des deutschen Idealismus, besonders das lebendige und organische Denken, finden später in der Lebensphilosophie Henri Bergsons (1859-1941) einen Widerhall. Wie der Franzose Bergson, vertritt der Biologe und Philosoph Hans Driesch (1867-1941) in Deutschland, von selbst durchgeführten, empirischen Betrachtungen der Natur ausgehend, eine Philosophie des Organischen, welche die metaphysische Einheit als Grundlage hat (vgl. STÖRIG 1995: 570-571). Statt vom Sinn in der göttlichen Einheit zu reden, redet man vom Sinn in der Einheit des Lebens. Somit tritt der Begriff des Lebens um die Jahrhundertwende als Grundmotiv für den Aufbau einer Weltanschauung auf, die auf dem Prinzip des Organischen beruht.

Was Döblins Versuch, dem Leben einen Sinn zu geben, anbelangt, kann man sagen, dass die Anhäufung vom „Ur“-Vokabular in seinem Werk Ausdruck dieser Sinnsuche ist. Die Einheit in der Dynamik des Werdens und Vergehens innerhalb einer organischen Weltstruktur, welche in Zusammenhang mit der Allbeseeltheit der Natur gedacht wird, wird durch „Ur“-Termini anders hervorgehoben, so dass Döblin dadurch in seinen Aussagen einen klaren Unterschied zu den rein materialistischen Darlegungen markiert. Die Absicht, Aspekte, die ausschließlich physikalisch-chemische Vorgänge und Reaktionen darstellen, durch „Ur“-Vokabular unter der metaphysischen Totalitätsidee zu bezeichnen, erinnert an Novalis’ „Romantisierung“ der Natur:

19 Darwins Deszendenztheorie stürzte das theologische Dogma der Unveränderbarkeit der Arten; Marx kritisierte im Anschluss an seinen historischen Materialismus die Funktion der Religion als „Opium des Volkes“; Nietzsche kritisierte das Christentum als Gründer einer „Sklavenmoral“ und predigte dagegen das Aufkommen des „Übermenschen“ durch die Überwindung christlicher Werte; letztlich fasste Freud den „Ödipuskomplex“" als Ursprung der Religion auf; vgl. KÜNG 1995: 264, 332, 385 bzw. 432-433; dazu vgl. KUNZMANN 1998: 171, 177 bzw. 189. 


\section{CORNELESEN, E. - Alfred Döblin, Naturphilosoph}

Die Welt muß romantisiert werden. So findet man den ursprünglichen Sinn wieder. Romantisieren ist nichts als eine qualitative Potenzierung. Das niedre Selbst wird mit einem bessern Selbst in dieser Operation identifiziert. So wie wir selbst eine solche qualitative Potenzenreihe sind. Diese Operation ist noch ganz unbekannt. Indem ich dem Gemeinen einen hohen Sinn, dem gewöhnlichen ein geheimnisvolles Ansehn, dem Bekannten die Würde des Unbekannten, dem Endlichen einen unendlichen Schein gebe, so romantisiere ich es. - Umgekehrt ist die Operation für das Höhere, Unbekannte, Mystische, Unendliche - dies wird durch diese Verknüpfung logarithmisiert - es bekommt einen geläufigen Ausdruck. [...] (HARDENBERG 1929a: 672-673) 20

Die Annahme einer metaphysischen Totalitätsidee bei Döblin entspricht der „Potenzierung“ der Natur bei Novalis. Die „Potenzierung“ ist der Faktor schlechthin, der der Natur einen anderen Charakter verleiht: Die Naturdinge sind nicht als einzelne Wesen, sondern im Verhältnis mit einem Ganzen zu denken und zu erforschen. In dieser Hinsicht sind „Ur“-Begriffe bei Döblin „potenzierte“ Bezeichnungen für die metaphysische Einheit der „potenzierten“ Natur in Form eines unpersönlichen Weltgesetzes, das sich als Dynamik des Werdens und Vergehens in einer organischen Weltstruktur ausdrückt. ${ }^{21}$

Eine weitere Motivation für den Gebrauch des „Ur“-Vokabulars, besonders was die Begriffe des „Ursinns“ und des „Urgrunds“ betrifft, kann Döblin im Taoismus gefunden haben. Das Interesse an Ostasien um die Jahrhundertwende verbindet sich auch mit der Zeitstimmung, ein anderes Weltbild zu finden, das in den Augen mancher Denker eine bessere Erklärung für den Sinn des Lebens anbietet als das christliche. Während im ausgehenden 18. Jahrhundert deutsche Denker vorwiegend den Konfuzianismus und den Buddhismus rezipierten, erweckten der Taoismus und erneut der Buddhismus zu Beginn des 20. Jahrhunderts das Interesse vieler Denker in Deutschland. Die eudämonische Harmonie mit dem Naturgesetz, mit dem Weltlauf und das

\footnotetext{
20 Zum Begriff der Potenzierung bei Novalis vgl. WANNING 1996: 74.

21 Wie Döblin macht der deutsche Naturforscher und Philosoph Ernst Haeckel (1834-1919) in seinem Meisterwerk Die Welträtsel. Gemeinverständliche Studien über Monistische Philosophie (1899) Gebrauch vom „Ur“Vokabular. Jedoch kann man einen wesentlichen Unterschied zwischen Haeckels und Döblins „Ur“Begriffen feststellen: Während bei Döblin meistens „Ur“-Begriffe zu finden sind, welche typisch philosophischer Prägung sind, wie „Urgrund“, „Ursinn“ und „Urmacht“, sind Haeckels „Ur“-Begriffe deutlich in der Naturwissenschaft verankert: „Urpflanzen“, „Urtiere“, „Urdarm“, „Urmund“, „Urwirbelbildung“, „Urfische“ und „Urmenschen“; vgl. HAECKEL 1961: 202, 205, 212, 213, 327, 247, 249, 252 bzw. 470. Der Grund hierfür liegt darin, dass Haeckel, anders als Döblin, an dem geschichtlichen Ursprung der Natur in Zusammenhang mit der Darwinschen Deszendenztheorie interessiert ist. Deswegen sind bei Haeckel Begriffe wie „Urpflanze“ nicht im Sinne von Goethes „Urpflanze“ zu verstehen. Denn nach Darwins Begründung der Deszendenztheorie wurde die ideale Bedeutung der „Urpflanze“ in eine geschichtliche Bedeutung umgewandelt, d.h. die „Urpflanze“ wurde fortan als Bezeichnung für historische Stammpflanze im naturwissenschaftlichen Bereich gebraucht. So kann man sagen, dass Döblin mit seinen „Ur“-Begriffen eine deutlichere idealistische Grundhaltung vertritt als Haeckel.
} 
„Tao“ als absolutes Weltprinzip sind die zentralen Lehrsätze der taoistischen Klassiker, die Döblin im Schaffensprozess seines "Chinesischen Romans“ gelesen hat. Der „Sinn“ (Chinesisch: „Tao“) tritt z.B. neben den Begriff des „Lebens“ (Chinesisch: „Te") als Maxime in Richard Wilhelms Übersetzung (1911/1912) von Laotses Tao-te-ching. Das Buch vom Sinn und Leben und Dschuang Dsis Das Wabre Buch vom südlichen Blütenland, welche Döblin, laut Walter Muschg, gekannt haben soll (vgl. MusCHG 1989: 487). Darüber hinaus sind einige „Ur“'-Termini in den von Richard Wilhelm übersetzten Werken der taoistischen Klassiker zu finden, wie „Urbild“ im Laotses Tao-te-ching (LAOTSE 1993: 35) und „Urgrund“ im Titel von Liä Dsis Das Wabre Buch vom quellenden Urgrund, dem Döblin Die drei Sprünge des Wang-lun widmet (DöBLIN 1989: 8). Ferner ist in Liä Dsis Werk die Rede von „Urwandlung“, „Uranfang“, „Urentstehen“, „Urschöpfung“ (Lï̈ DSI 1992: 34), und in Dschuang Dsis Das Wabre Buch vom südlichen Blütenland treten weitere „Ur“Begriffe auf, wie „Ur-Reinheit“ und „Uranfang“ (Dschuang DsI 1992: 105, 134 bzw. 290).

Im Anschluss an die Interpretation des „Ur“"-Vokabulars möchte ich die Interpretation von Das Ich über der Natur wieder aufnehmen. Döblin macht in Das Ich über der Natur zwar Gebrauch von Ergebnissen, die empirisch belegt werden können. Eine physikalisch-chemische Betrachtungsweise steckt hinter seinen Darlegungen zum Verhältnis von Mensch und Natur. Die Art und Weise, wie Döblin hier zugunsten des „Ur-Ich“ argumentiert, erinnert gewissermaßen an das „Religionsgespräch“ Der unsterbliche Mensch (1946) nach seiner Bekehrung zum Katholizismus. Er sucht Schritt für Schritt mittels einer deduktiven Methode die Existenz des „Anonymen“ zu beweisen. Döblin behauptet so z.B. erneut, dass die Zeichen der Allbeseeltheit der Natur, die vom Organischen bis ins Anorganische reichen, sich durch Ordnung, Zahl, mathematische Gesetze, Zweck und Gliederung ausdrücken ließen (vgl. DöBLIN 1928: 7). Das Ich, das Individuum tritt damit als „Ort der einzelnen Seele“ (DöBlin 1928: 110) auf, die ihrerseits von den Seelen im Organischen und Anorganischen gebildet wird. Nach der Herkunft der Seele will Döblin nicht fragen, denn für ihn sind die Lebewesen nach seiner monistischen Auffassung, in der die dualistische Trennung von Leib und Seele aufgehoben wird, „von Haus aus beseelt“ (DöBLIN 1928: 110). Die Kosmogonie und die Theogonie sind zu jener Zeit einige der Themen, die Döblin bei seinem Philosophieren über die Natur häufig vermeidet. Nur am Rande der Diskussion lehnt er die Idee eines Schöpfergottes ab, der die Materie belebt, und die Idee einer „Urzeugung“ (DöBLIN 1928: 99). Statt dessen glaubt er an 
„die große anonyme Gewalt“ (DöBLIN 1928: 42) und an ein „Urvorhandensein“ (DÖBLIN 1928: 99) der beseelten Wesen. Deshalb ist darauf hinzuweisen, dass die Allbeseeltheit der Natur bei Döblin im Zusammenhang mit Betrachtungen zu Aspekten physichalisch-chemischer Art zu verstehen ist.

Döblins Naturerkenntnis geht also über die Rekonstruktion mittels der Mathematik, Chemie und Physik, und so, wie bereits erwähnt, über die Erkenntnis der exakten Wissenschaften hinaus. Er begnügt sich nicht damit, bestimmte Naturmerkmale wissenschaftlich zu erkennen. Er muss die ihm vernünftig erscheinende organische Struktur der Welt in Zusammenhang mit einer höchsten Naturinstanz setzen, damit der organischen Weltstruktur eine metaphysische Einheit in der Vielheit der Naturdinge deutlicher angeboten wird als bisher. Die Erkenntnis der rationalen Konstante in der Weltgestaltung als Anlass zum Gottesbeweis war übrigens seit Nikolaus Kopernikus (14731543) in der Wissenschaftsgeschichte geläufig. Mit einem als rational und vernünftig orientierten Weltmodell will Döblin aber anderes erreichen als einen Gottesgedanken, in dem sowohl Gottes Wille und Gnade, als auch Gottes Eingreifen in die Schöpfung die zentrale Rolle spielen. Döblin wagt es, nicht nur die Natur als Ganzes, als Totalität zu verabsolutieren, sondern diese Totalität für den Ausdruck des „Anonymen“ zu halten. Er hegt keine Bedenken, das Erkenntnis zu nennen, was er mittels objektiver Naturerkenntnis nicht beweisen kann. Das Problem liegt schon in der Art und Weise, wie er sich dem Gegenstand seiner naturphilosophischen Spekulationen nähert - besser gesagt, wie er sich von ihm im Grunde entfernt -: In ihrer „All-Einheit“ kann die Natur letzten Endes, wie Kant richtig aufzeigt, überhaupt „nicht Gegenstand möglicher Erkenntnis sein“ (ZAHN 1989: 110).

Es geht in Das Ich über der Natur um eine über die erfahrbare, natürliche Welt hinausgehende, metaphysische Gedankenführung, denn Döblin versucht den letzten Gründen und Zusammenhängen des Seins einen Sinn zu geben. Außerdem geht es darin zugleich um die einzige Möglichkeit der menschlichen „Rettung“ aus einem mangelhaften Zustand: die Macht des Erkennens und des Denkens. Die Kraft des Erkennens enthält, so meint Döblin, den Lebenssinn und das Ziel der menschlichen Existenz. Die Kraft, die zur Überwindung der Zeitlichkeit und des Leidens dienen kann, liegt im Erkennen der Zusammenhänge zwischen Welt und Daseinsformen, zwischen Totalität und Pluralität. Erkennen bedeutet hier Handeln und Leben als 
Selbstverwirklichung nach den Möglichkeiten des „Ur-Sinns“ und des „UrIch“, welche nach Döblin diese Zusammenhänge äußern.

Das Ich über der Natur ist in drei Kapitel gegliedert: „Die Ausbreitung des Sinns in der Natur“ (DöBlin 1928: 11-93), „Das Ich über der Natur“ (DöBlin 1928: 97-181) und „Die Ziele“ (DÖBLIN 1928: 185-242). Im ersten Kapitel geht es um Döblins Versuch, aus der Natur heraus dem Leben einen Sinn zu geben. Allbeseeltheit der Natur, elementare Kräfte wie die des Feuers und Wassers, die organische Struktur der Natur, sowie Merkmale wie Entformung, Umseelung, Bewegung und Angleichung werden zu diesem Zweck darin thematisiert. Im zweiten Kapitel wird dann das Ich, das Individuum als Gegenstand von Döblins Spekulationen ins Zentrum gerückt. Schließlich wird im dritten Kapitel die Existenz eines „Ursinns“ in der Welt erörtert und für die „Wiedergeburt der Hauptwissenschaft Theologie“ (DÖBLIN 1928: 242) plädiert. Außerdem werden am Ende des Buchs zehn Leitsätze aufgelistet, sozusagen „zehn Gebote“, in denen die Hauptgedanken von Döblins Darlegungen zur Existenz des „Anonymen“ zusammengefasst werden:

\section{LEITSÄTZE}

I

Es gibt nur beseelte Wesen in der Natur; auch die chemisch-physikalische Natur ist beseelt.

II

Zeichen der Beseelung ist die sinnvolle Ordnung, von der zahlenmäßigen Gliederung bis zur Schönheit.

III

Das Ich stellt sich dar in der äußeren Formung der organisierten Wesen, in der inneren, gesetzmäßigen Formung der anorganischen Wesen, in der Ordnung der Zusammenhänge.

IV

Es ist kein Stoff und keine Form in der Natur zu treffen, sondern nur geformte Wesen und Vorgänge.

$$
\mathrm{V}
$$

Die Welt stellt im ganzen die vieldimensionale Äußerung eines Ur-Ichs, eines Ur-Sinns dar.

VI

Die physikalische Welt ist unvollständig und daher nicht real. Die wirkliche Welt ist weder endlich noch unendlich, sondern bestimmt, das heißt charaktervoll geformt. Die Welt hält sich und wird real durch eine Überrealität, welche aus dem Ur-Ich, dem Ur-Sinn stammt. 


\section{CORNELESEN, E. - Alfred Döblin, Naturphilosoph}

VII

Die Einzelwesen und die vergängliche Welt haben eine charakteristische Realität-Irrealität.

VIII

Es gibt keine Entwicklung in der Zeit, trotzdem ist die Welt sinndurchgeflossen.

IX

Das Ur-Ich, wenn auch in der Verkrümmung der Zeit und der Vereinzelung, ist in jedem Wesen. Wie das Einzelne nicht real ist ohne das Ur-Ich, ist das Ur-Ich nicht ohne das Einzelne. Das Einzelne wirkt so als Täter und Schöpfer der Welt.

\section{$\mathrm{X}$}

Da die Welt, von einem Ich getragen, von geistiger Art ist, ist das Erkennen eine große Macht. Wir haben dies Vermögen in uns. (DöBLIN 1928: 243 244)

Die ersten vier „Leitsätze“ bringen dieselben Aussagen, welche Döblin in den vorhergehenden naturphilosophischen Aufsätzen vertreten hat. „[V]ieldimensionale Äußerung“, Unvollständigkeit der Welt, und „RealitätIrrealität" als das Charakteristische der Einzelwesen und der vergänglichen Welt werden dann in Zusammenhang mit einer „Überrealität“ in den vier nächsten „Lehrsätzen“ gesetzt. Damit betont Döblin folgendes: Diese „Überrealität“ ist nur in ihrem dynamischen Charakter zu verstehen, d.h. sie kommt nie zur Vollendung. Dies erinnert an Döblins Kritik an dem Verfahren, Personenbegriff und das „Anonyme“ zusammenzubringen (vgl. DÖBLIN 1922: 9). ${ }^{22}$ Denn diese „Überrealität“ darf in ihrem unvollendeten Charakter keineswegs unter einem Personenbegriff aufgefasst werden. Darüber hinaus erläutert Döblin in den letzten zwei „Lehrsätzen“, was er genau mit „Ur-Ich“ meint: Die alles umfassende Tendenz zur organischen Bildung in der Natur ist das „Ur-Ich“, die natura naturans, die sich als Geistiges, als Denkendes sowohl in der Vielfalt der Naturdinge als auch in ihrer unbeschränkten Ganzheit ausdrückt. Das Erkennen dieser Tendenz ist für Döblin das höchste Ziel, das dem Leben als Ganzem einen Sinn geben würde.

Bei der Interpretation der Einzelkapitel von Das Ich über der Natur, was die höchste Naturinstanz betrifft, ist festzustellen, dass in jedem Kapitel immer eine bestimmte Bezeichnung der höchsten Instanz herrscht: „das Weltwesen“ (DÖBLIN 1928: 68, 84, 90 und 93) im ersten Kapitel; „das Anonyme“ (DÖBLIN 1928: 174, 177, 178, 179 und 180) im zweiten Kapitel; schließlich das „Ur-Ich“ (DÖBLIN 1928: 203, 204, 214, 230, 243 und 244) im

\footnotetext{
22 Dazu vgl. CORNELSEN 1999: 228.
} 
dritten Kapitel. Es ist von Bedeutung, dass die Bezeichnung der höchsten Naturinstanz, die am häufigsten vorkommt, ihr Hauptmerkmal als denkendes und der Welt Sinn spendendes Wesen unterstreicht: der „Ur-Sinn“ (DÖBLIN 1928: 7, 8, 42, 68, 117, 149, 168, 171, 172, 173, 177, 180, 181, 200, 205, 211, 213, 214, 216, 217, 218, 219, 222, 226, 241, 243 und 244). Außerdem versieht Döblin im ganzen Buch die höchste Naturinstanz mit mehreren wesentlichen Merkmalen: Anonymität, Gewalt, Universalität, Überpersönlichkeit, Größe, Unermüdlichkeit, Übernatürlichkeit und Übermacht.

Döblin beginnt sein erstes großes naturphilosophisches Werk mit einem Angriff auf positivistische Wissenschaftler, die nur dies für wahr halten, was sie exakt mittels wissenschaftlicher Erkenntnisse belegen können und daher als Vorkämpfer eines mathematischen Rationalismus fungieren. Dagegen sieht er statt Physik allein die „Metaphysik“, und statt Psychologie allein die „Metapsychologie“ (DöBLIN 1928: 66) als adäquate Wissenschaften, die zu einer Deutung der Welt verhelfen können. Er ist sich dessen bewusst, dass manche seiner Darlegungen höchst spekulativ sind, obwohl sie ihre Wurzeln in naturwissenschaftlich orientierten, empirischen Beobachtungen zu haben scheinen. Dies liegt offensichtlich an dem methodischen Verfahren, auf dem dieses Werk beruht. Einerseits verzichtet Döblin keineswegs auf eine wissenschaftliche Methode, denn er bedient sich vieler Ergebnisse aus der Naturwissenschaft. Andererseits geht er darüber hinaus, denn er weiß von vornherein, dass die sinnvolle Totalität der immanenten, elementaren Naturkräfte durch reine Empirie nicht bewiesen werden kann. Döblin erkennt die Grenzen der Naturwissenschaft. Jedoch begnügt er sich nicht damit, sie scharf zu kritisieren. Er will diese Grenzen überschreiten, um zu beweisen, was wissenschaftlich unbeweisbar bleibt.

Andererseits bewegt sich der Naturwissenschaftler Döblin auf dem Boden der reinen Spekulation. Auf diese Weise sucht Döblin mittels spekulativer Haltung aus der Sinnlichkeit und der Vernunft, durch Betrachtung der Natur, die Existenz eines „Ursinns“ in ihrer Totalität zu beweisen. Dies ist ein Aspekt, der Döblin beim Philosophieren eine zurückgreifende Hinwendung zur Metaphysik nehmen lässt. Die Tatsache, dass der Aufschwung des positivistischen Denkens schon längst die Metaphysik als „Wirklichkeitsfälscher“ (vgl. SCHMIDT 1991: 479) stempeln ließ, scheint Döblin infolgedessen bekämpfen zu wollen, um die Welt im Sinne von Novalis zu „romantisieren“. 
Darüber hinaus muss man sehen, dass der „Geist des naturalistischen Zeitalters", den Döblin besonders in den zwanziger Jahren herzlich feiert, viel vom "Geist" der Aufklärung hat. Denn der Durchbruch in der Naturwissenschaft des 19. Jahrhunderts findet seine Wurzeln im Einsatz der Mathematik und in der Methode der Beobachtung durch die Aufklärer, welche eine Fülle von wissenschaftlichen Entdeckungen in relativ kürzer Zeit ermöglichten. Gewiss bleibt Döblin trotz seiner Kritik an der positivistisch verankerten Physik, vor allem was die naturwissenschaftliche Methode betrifft, ihrer rationalistischen Grundlage verhaftet. Döblin sieht aber in der Bewältigung der Natur durch Wissenschaft und Technik eine Gefahr, die ihn dazu führt, einen anderen Weg zu nehmen als den der positivistischen Naturwissenschaftler seiner Zeit. So gesehen, kann man daraus schließen, dass Döblins Verlangen nach der Rückwendung zur Metaphysik dazu dienen soll, zu zeigen, dass die Bewältigung der Natur anders gedacht werden soll: Der Mensch ist nur ein aktiver, aber winziger Teil innerhalb der ewigen gesamten Natur. Infolgedessen ist die Rückwendung zur Metaphysik bei Döblin in Verbindung mit ethischen Gedanken zu verstehen, die das Ideal einer Eudämonie, im weiteren Sinne des Handelns im Einklang mit der Natur besser erfüllen als diejenigen der Naturwissenschaft in ihrer positivistischen Einschränkung der Naturbetrachtung. ${ }^{23}$

Wie bereits erläutert, sind Döblins naturphilosophische Spekulationen ein Versuch, die Natur sowohl mittels unmittelbarer Sinnlichkeit als auch mittels der Erkenntnisse der Naturwissenschaft zu deuten, um das Dasein einer Naturinstanz, die alles umfasst und zugleich sein Dasein in allen Naturdingen und -vorgängen findet, und dessen Eigenschaften begrifflich zu erschließen. Dazu führt er kosmologische Beweise, d.h. er schließt von der Gesetzmäßigkeit und Ordnung der Natur auf eine die Welt denkende Naturinstanz.

Außerdem spricht Döblin in Das Ich über der Natur von den verschiedenen „Seiten“ des menschlichen Ich. Dazu entwickelt er seine eigene

\footnotetext{
${ }^{23}$ Was den Positivismus mit der Aufklärung verbindet, ist der mathematische Rationalismus. Als Gründer des wissenschaftstheoretischen Systems des Positivismus gilt der Franzose August Comte (1798-1857). Wie die Aufklärer, etwa Holbach oder Lamettrie, hält Comte die Metaphysik für eine Fälschung der Wirklichkeit. In seiner Auffassung sind alle Versuche, die Erscheinungen der Welt in Zusammenhang mit irgendwelchem übernatürlichen Wesen zu setzen, bloße Abstraktionen; vgl. KUNZMANN 1998: 165; dazu vgl. KÜNG 1995: 199. Infolgedessen erklärt Comte metaphysische Erörterungen für theoretisch unmöglich, und beschränkt dagegen die Forschung auf das „Positive“, d.h. auf das Gegebene, Tatsächliche, Sichere, Zweifellose; vgl. SCHMIDT 1991: 550-551. Dies hat ihre Folgen für die Naturwissenschaften: Die Gesetzmäßigkeit in der Natur, welche die Naturwissenschaften mittels empirischer Methode erforschen, wird in keinen Zusammenhang gebracht, der die metaphysische Idee einer Totalität stützen würde. Hier liegt der Kern von Döblins Kritik an dem positivistischen Verfahren der Naturbetrachtung.
} 
„metapsychologische“ Betrachtung: Diese soll eine Art Seelenlehre sein. Sie erinnert an die Schichtung der Triebe im Organischen, die Döblin im Aufsatz „Die Natur und ihre Seelen“ formuliert: „Bestialtriebe“, „Organtriebe“, „Humantriebe“ und „Gesellschaftstriebe“ (DöBLIN 1922: 6). ${ }^{24}$ Nach Döblin befindet sich das menschliche „Ich“ in einem Wirkungszusammenhang. Es ist Teil eines „universellen Ur-Ich“ (DÖBLIN 1928: 151) und zugleich die Totalität anderer fragmentierter „Ichs“: Das „Einzel-Ich“ (DöBLIN 1928: 155) wird von Döblin in das „Natur-Ich“ (DöBLIN 1928: 155), „Passions-Ich“ (DöBLIN 1928: 156), „Privat-Ich“ (DöBLIN 1928: 151), „Aktions-Ich“ (166) und „Gesellschafts-Ich“ (DÖBLIN 1928: 156) unterteilt. Diese Schichtung des „Ich“ folgt aus der Annahme, die besagt, dass der Mensch weder Zentrum von sich selbst sei, noch einen privilegierten Platz über andere Naturdinge im Weltall einnehme. Im „Natur-Ich“ sieht Döblin die Verbindung des „EinzelIch“ zur Natur, die ihrerseits in seiner biologischen Struktur wirkt und sich mit physiologischen Aspekten assoziiert. Das „Passions-Ich“ und das „Gesellschafts-Ich“ binden das „Einzel-Ich“ ans Milieu, d.h. sie formen das Individuum in ein Kollektivwesen um. Erst das „Privat-Ich“ überträgt dem „Einzel-Ich“ den eigentlichen individuellen „Ich-Charakter“. Als „AktionsIch“ stellt das „Einzel-Ich“ auch eine handelnde Haltung zum Eingreifen in die Weltgeschichte dar. Döblin fordert den Menschen auf, „kein[en] Fatalismus, keine Resignation“ (DöBLIN 1928: 227) zu empfinden, da der Mensch am Vollzug der Welt beteiligt ist, wie alle Naturdinge.

Wie erläutert, unternimmt Döblin bei seiner Naturphilosophie eine Zusammensetzung von Organischem und Anorganischem. Anorganische und organische Natur werden dabei in einem ständigen Verhältnis von Bildung und Auflösung, von Kontinuität und Diskontinuität, von Formung und Entformung dargestellt (vgl. DöBLIN 1922: 9). ${ }^{25}$ Die „Umseelung“ (DöBLIN 1928: 42) ist daher der Prozess der Auflösung der organisch gebildeten Seele der Naturwesen ins Anorganische und der daraus folgenden Bildung anderer organischer Wesen. In einer Art ständiger Schöpfung in der Natur durch die „Urkräfte“ herrschen zugleich Zeitlichkeit und Ewigkeit: Die geformten Naturdinge sind zeitlich, das denkende „Ur-Ich“ zugleich zeitlich und ewig: Es ist ewig, indem die einzelnen Urkräfte unerschöpflich (vgl. DÖBLIN 1928: 176) und das „Anonyme“ als Ganzes unermüdlich (vgl. DöBLIN 1928: 180) sind; zeitlich, indem das „Weltwesen“ in Form vielfältiger Naturdinge in die Zeit eintritt (vgl. DöBlin 1928: 171), d.h. die alles umfassende Tendenz zur

${ }^{24}$ Dazu vgl. CORNELSEN 1999: 225.

${ }^{25}$ Dazu vgl. CORNELSEN 1999:.228.

Pandaemonium germanicum 11/2007, 45-76- www.fflch.usp.br/dlm/alemao/pandaemoniumgermanicum 
organischen Bildung in der Natur durch Kräfte des Anorganischen ist als solche ewig, ihre Konkretisierung in individuellen, organischen "Ichs“ hingegen zeitlich. Das Anonyme ist als einheitliche Instanz somit „der Ort der ,unsterblichen' Seele“ (DÖBLIN 1928: 177). Alles ist Erscheinung des Anonymen in der Zeit: „Glanz, Duft, Licht, Finsternis, Säure und Süße, Schwere, Flüssigkeit, Strahlen“ (DÖBLIN 1928: 200).

Darüber hinaus hält Döblin den Prozess von Geburt, Leben und Tod für einen vorübergehenden Zustand. Wie er bereits im Aufsatz „Die Natur und ihre Seelen“ darlegt, garantieren „Umbildungen, Entseelungen, Umseelungen“ (DöBLIN 1928: 116) das Kontinuum der „Körper-Beseeltheit“ (vgl. DöBlin 1922: 9). ${ }^{26}$ Am Individuum haftet der Tod. Aber der Tod bedeutet kein Ende, denn der Körper des Individuums teilt sich wieder in elementare „Individuen“ und „Urstoffe“, wie z.B. in Wasser und Salze. Der Tod soll damit nicht als letzte Stufe des Lebens verstanden werden, sondern als eine Entformung, d.h. der Verwesungsprozess entformt das Wesen und bildet neue Formen, die weiter beseelt sind: ,[...] das zusammenhaltende Ich gibt alle Organe frei; sie hören auf, Organe zu sein; sie werden Zellen, nicht einmal Zellen, nur Flüssigkeit, Gallerte, Schaum, chemischer und physikalischer Körper.“ (DÖBLIN 1928: 105)

Döblin sucht einen Weg, dem Leiden in seiner Deutung des „Ur-Ich“ einen Platz zu geben, ohne das „Ur-Ich“ damit negativ zu besetzen. Für ihn ist das Leiden „eine metaphysische Mitgift“, „das Wissen um die Individuation“ (DÖBLIN 1928: 241): „Der Schmerz, das Leiden, das ist der unermüdliche Ruf des Ursinns in den Wesen. Wir schwanken zwischen der Lust, zu sein, und dem Schmerz, nicht ganz zu sein.“ (DÖBLIN 1928: 241)

Damit vertritt Döblin dieselbe optimistische Idee, die er im Aufsatz „Buddho und die Natur“ (1921) verkündet hat: Lust und Schmerz sind mithin als Kennzeichen des Naturwesens anzusehen. Wer ja zur Lust sagt, so Döblin, muss dann den Schmerz als Existenzbestand auch bejahen (vgl. DöBlin 1921: $1194-1195) \cdot{ }^{27}$

Döblin zeigt in Das Ich über der Natur auch, dass das Leben einer immer bedrohten Gleichgewichtung von Gegensätzen ausgesetzt ist. Die Struktur des Weltalls besteht nach Döblin also im Wechsel von Konstruktion und Destruktion. Trotz Umformung der Naturwesen gibt es nach seiner

${ }^{26}$ Dazu vgl. CORNELSEN 1999: 228.

27 Dazu vgl. CORNELSEN 1999: 59. 
Auffassung eine „Angleichung“ (DöBLIN 1928: 47), die zu einer „Gleichgewichtslage“ (DÖBLIN 1928: 49) führen würde. ${ }^{28}$

Aus Döblins Glaube an die Wirksamkeit eines immanenten, in der Totalität der elementaren Naturkräfte gedachten Instanz ergibt sich eine besondere Haltung der Natur gegenüber. In seinem Versuch, den Gottesbegriff der jüdisch-christlichen Tradition durch den Begriff des „UrIch“ („Ursinns“) zu ersetzen, will Döblin die Natur, in welcher der alles umfassende „Ursinn“ waltet, mit Merkmalen beladen, welche normalerweise Gott allein zugesprochen werden. Auf diese Weise werden Naturdinge für „heilig“ erklärt, weil sie Zeugnis von etwas Elementarem, Kräftigem und Schönem sind. Dies lässt sich besonders in der Passage nachweisen, in der Döblin Buddhas pessimistische Weltsicht erneut kritisiert und vom Anbetungscharakter der Naturdinge spricht (vgl. DöBLIN 1928: 151). Döblin sieht in einer Haltung zur Natur, die im „Ur-Ich“ ihre höchste Instanz findet, das Mittel zur „Reinigung der Gesellschaft“ (DÖBLIN 1928: 149). Dazu fordert er ,Verehrung und Anbetung der großen Naturkräfte und des Ursinns“ (DÖBLIN 1928: 149): „Früher suchten die Menschen sich krampfhaft und ekstatisch in „Gott“ einzustellen. Jetzt sollen sie sich regenerieren im Umgang mit Steinen, Blumen, fließendem Wasser.“ (DÖBLIN 1928: 150) ${ }^{29}$

Indem Döblin den Gottesbegriff nicht nur ablehnt, sondern ihn durch eine höchste Naturinstanz als Ausdruck für die metaphysische Einheit des Ganzen ersetzen will, stellt er die Natur als Anbetungsobjekt unmittelbar an die Stelle Gottes. Dies würde ich hier im Sinne eines Appells Döblins an die Menschen interpretieren, die Natur anders - genau als natura naturans - zu verstehen, statt sie als geschaffene Natur unter der ausschließlichen Wirkung ihres Schöpfers aufzufassen. Für Döblin geht es hier nicht um die Kräfte einer persönlichen, göttlichen Instanz, sondern um die Kräfte der Natur, welche in

\footnotetext{
28 Axel Eggebrecht weist zutreffend darauf hin, dass Döblin Charles Darwin gegenüber tritt: Während Darwin einen Wandel der organischen Welt im „Kampf ums Dasein“ behauptet, unterstreicht Döblin dagegen die Angleichung des Mangels durch Komplementierung, die in der Natur ein Gleichgewicht herstellen würde; vgl. EGGEBRECHT 1972: 197. Im Aufsatz „Krieg und Frieden“ (1920) lehnt Döblin übrigens die Idee des „Kampfs ums Dasein“ deutlich ab, weil nach seiner Sicht der „Gesellschaftstrieb“, der zur „Angleichung“ führt, etwas in der Natur Gegebenes, also Nicht-Entwickeltes ist:

[...] Denn [nicht] die Fähigkeit der Menschen, sich an Terrainschwierigkeiten anzupassen, Witterungswechsel auszuhalten, Kälte und Hitze zu ertragen, Tiere zu töten oder ihnen zu entgehen, hat es ihnen ermöglicht, eine fast unbehaarte Haut zu haben und doch nicht zu erfrieren, schlecht zu klettern, schlecht zu sehen, kaum zu riechen, mäßig zu laufen und doch leben zu bleiben, sondern der Gesellschaftstrieb, der unbedingt von Haus aus und vor den gefährlichsten Erfahrungen in ihnen vorhanden gewesen sein muß. Ich nehme es nicht hin, wenn einer erklärt: diese Kraft ist im Kampf ums Dasein einmal entstanden und in der Auslese seiner Besitzer vererbt. Im Kampf „entsteht“ überhaupt nichts; der Kampf ist nicht produktiv. Produktiv und plastisch ist der lebendige Organismus. [...]; DÖBLIN, 1972b: 161.

${ }^{29}$ Hier zitiert Döblin dieselbe Passage vom Aufsatz „Buddho und die Natur“; vgl. DöBliN 1921: 1200 bzw. CORNELSEN 1999: 59.
} 
der Totalität ihrer physikalisch-chemischen Äußerungen als Sinn, genau als „Ursinn“, weil in der Natur immer vorhanden, wahrgenommen werden sollen.

Döblin endet Das Ich über der Natur mit der Forderung, eine Disziplin sollte die Aufgabe erfüllen, welche die positivistisch orientierte Wissenschaft wenig oder gar nicht pflegt, nämlich die Aufgabe, über das Wissen und das ignoramus-et-ignorabimus ${ }^{30}$ der Wissenschaft hinauszugehen und sich doch mit jenem Wissen zu beschäftigen, das man seiner Meinung nach falsch Glauben nennt: die Theologie. Die Forderung der "Wiedergeburt der Hauptwissenschaft Theologie“ (DÖBLIN 1928: 242) ist bei Döblin nicht im Sinne einer Rehabilitation religiöser Dogmen zu verstehen, sondern als eine Enneuerung der Religion ausgehend sowohl von der Ablehnung der dualistischen Trennung von Jenseits und Diesseits als auch von der Unbrauchbarkeit des Gottesbegriffs. In dem ganzen Buch kann man einen anti-kirchlichen Affekt ausmachen. Das Ich über der Natur ist in erster Linie Kampf gegen den je institutionalisierten jüdisch-christlichen Gottesgedanken. Döblin setzt sich daher mit religiösen Aspekten auseinander, zu dem Zweck, sie abzulehnen und zugleich durch eine neue „Religion des Ur-Ich“, hier im weiteren Sinne gedacht durch eine „gottlose Mystik“, um mit Fritz Mauthners (1849-1923) unpräziser Formel weiter zu argumentieren, ${ }^{31}$ zu überwinden. Ein Beispiel dafür bildet Döblins Kritik am biblischen Sündenfall - er fasst 1 . Buch Mose 3 zusammen -, vor allem deshalb, weil nach seiner Interpretation das Leiden als etwas exklusiv Menschliches darin auftritt, während er der Meinung ist, dass auch Tiere und Pflanzen leiden. Außerdem ist er gegen die Idee einer Auferstehung nach dem Tod oder eines göttlichen Gerichts, denn für ihn ist der Tod überhaupt kein Endpunkt, sondern Auflösung und Umformung (vgl. DöBLIN 1928: 215).

Trotz der Ablehnung der Dogmen der monotheistischen Offenbarungsreligionen will Döblin die Rolle der Religion positiv betrachten. Wie in Reise in Polen weist Döblin in Das Ich über der Natur erneut darauf hin, dass die Religion neben Wissenschaft als Vermittlerin der Wahrheit ihre Gültigkeit hat (vgl. DöBlIN 1993: 329-330). ${ }^{32}$ Er präzisiert jedoch, was er mit Religion meint, indem er die Frage stellt, ob Religion „Opium“ ist, wie seit

\footnotetext{
30 Der Physiologe Emil Du Bois-Reymond (1818-1896) hat im Jahre 1872 das Schlagwort für die Unlösbarkeit der Welträtsel geprägt. Er war gegen die Übertragung subjektiver Aspekte auf die Materie. Aufgrund der Legitimation der naturwissenschaftlichen Weltdeutung sollte man daher den Erkenntnisanspruch der Naturwissenschaft begrenzen; vgl. SCHмIDT 1991: 324.

31 Zur Problematik der Formel ,gottlose Mystik“vgl. MAUTHNER 1963: 428 bzw. CORNELSEN 1999: 250.

32 Dazu vgl. CORNELSEN 1999: 71.
} 
Marx besonders von den Kirchengegnern behauptet wird. ${ }^{33}$ Er argumentiert, dass man den Satz „Religion sei Opium“ auf zwei verschiedene Weisen bewerten kann: als gut, wenn dadurch kritisch erläutert wird, dass die Religion dem Menschen die Verantwortung nimmt; als schlecht, wenn dieser Satz die Existenz eines „Anonymen“ leugnet, das in dem und durch das Individuum wirkt. Darüber hinaus klassifiziert er die Religion auch unter den Kategorien des Guten und des Schlechten: Religion sei gut, wenn sie "um unsere Abkunft vom sinnspendenden Ur-Ich weiß” (DÖBLIN 1928: 238); sie sei aber schlecht, wenn sie im Gegensatz dazu "das Anonyme ins Jenseits verlegt" (DÖBLIN 1928: 238): „Indem sie [d.h. die Religion] Gott ohnmächtig über mich und mich ohnmächtig unter Gott stellt, ist sie wider Gott. Solche Religion ist schlimmer als Atheismus, nämlich Paratheismus." (DÖBLIN 1928: 238)

Darüber hinaus wiederholt Döblin des öfteren am Ende der naturphilosophischen Schrift Das Ich über der Natur den Satz „das Urwesen ist nah“ (DÖBLIN 1928: 236-237). Hier würde ich diesen Satz als eine Anspielung auf Matthäus 3, 2 und 4, 17 über die Nähe des Reichs Gottes interpretieren, aber nicht im Sinne einer Erlösung oder einer Verwirklichung des Reichs Gottes wie in der Bibel, sondern im Sinne der Erkenntnis, dass das Urwesen, laut Döblin, „keine fremde Gewalt“ (DöBLIN 1928: 236) sei: Es kann in den Naturwesen als ,geistige“"Kräfte erkannt werden.

Seele, Geist, Anbetung, Heiligkeit bilden die Begrifflichkeit, die in religiösen Aussagen geläufig ist und von Döblin in Das Ich über der Natur erneut gebraucht wird. Mit solcher Begrifflichkeit grenzt Döblin seine metaphysisch verankerten Spekulationen deutlich von rationalistischen Aussagen des positivistischen Materialismus ab, obwohl er keineswegs auf die naturwissenschaftlichen Ergebnisse verzichtet, um das Verhältnis von Mensch und Natur zu erörtern. Gewiss bedeutet Religion (Lateinisch: „religare“, anbinden, festbinden, ,etwas wiederholt und sorgfältig beachten“) (SCHMIDT 1991: 583) im allgemeinen eine Weltanschauung und Lebensführung, die vom Glauben an die Existenz Gottes oder einer Gottheit bestimmt wird, die ihrerseits dem Ganzen einen Sinn gibt:

\footnotetext{
33 Im Aufsatz „Kritik der Hegelschen Rechtsphilosophie“ (1844) formulierte Karl Marx (1818-1883) den berühmten Satz „Sie [d.h. die Religion] ist das Opium des Volkes“. Marx Religionskritik lässt sich, wie Hans Küng zutreffend erörtert, vor allem von dem Vorwurf ableiten, dass die Religion als „Beruhigung und Betäubungsmittel“ wirkt und „illusorisches statt wirkliches Glück verschafft“, indem sie „von dieser diesseitigen Welt und ihrer Veränderung auf ein Jenseits ablenkt und vertröstet“; KÜNG 1995: 264; dazu vgl. KUNZMANN 1998: 171.
} 
[...] Religion zeigt sich dann als eine Weise menschlichen Existierens aus der Relation zu einem (nicht noch einmal zu überschreitenden und in diesem Verständnis „letzten“) Sinn-Grund, der also das schlechthin Gründende und Sinnspendende die Deutung des Seienden im Ganzen sowie aller Seinsbereiche (Mensch, Welt, Geschichte, Gesellschaft, Recht, Sittlichkeit, Kultur, Sprache, Wirtschaft usw.) betrifft. [...] (HÖFER \& RAHNER 1963: 1165-1166)

Wenn Religion allein in diesem Sinne zu verstehen wäre, dann sollte man zugeben, dass es sich bei Döblins naturphilosophischen Spekulationen über das „Ur-Ich“, über den „Ursinn“ in Das Ich über der Natur um eine „Religion“ handelt. Jedoch weise ich darauf hin, dass diese „Religion“ von der Begrifflichkeit her keineswegs als weit ausgeprägte Vorstufe zu Döblins Konversion zum Katholizismus in den vierziger Jahren zu verstehen ist, sondern eben als eine „Ersatzreligion“, ${ }^{34}$ die ihre Wurzeln in Döblins Religionskritik der zwanziger Jahre hat. Sie befindet sich in diametraler Position zu denjenigen Religionen, die personale Gottesvorstellungen und Jenseitsglauben als ihren Kern besitzen, wenn sie u.a. die Gottesoffenbarung leugnet, Immanenz statt Transzendenz als Grundlage hat, Gott das zentrale Attribut der Person - zusammen mit allen anderen Attributen wie Gnade, Barmherzigkeit, Vorsehung, Wille, Gerechtigkeit ${ }^{35}$ - und die Sonderstellung des Menschen gegenüber anderen Naturwesen leugnet.

Zum Schluss weise ich erneut darauf hin, dass Döblins „beseelter“ Naturalismus, den seine Bekehrung zum Katholizismus später überwindet, als eine Art Ersatz für das lange herrschende Weltbild des Christentums gedacht wird. Daraus entsteht Döblins heftige Religionskritik der zwanziger und dreißiger Jahre, die weniger gegen die Religion selbst, als vielmehr gegen Gottesvorstellungen und Jenseitsglauben gerichtet wird, wie man dies sowohl im Aufsatz „Der Geist des naturalistischen Zeitalters“ als auch in den Abhandlungen Das Ich über der Natur und Unser Dasein feststellen kann. Denn für ihn gilt die Religion neben der Wissenschaft als Vermittlerin der Wahrheit, und weder Wissenschaft noch Religion sollen für sich allein diese Wahrheit in Anspruch nehmen. Somit kann man eindeutig feststellen, dass Döblin beim Philosophieren über die Natur einen mittleren Weg zwischen Tradition und Moderne vorschlagen will, der durch die Verbindung von metaphysischen und naturwissenschaftlichen Aussagen zur Sprache gebracht wird. Aber Döblin spart nicht mit Kritik, wenn es um eine bestimmte Haltung gegenüber der

\footnotetext{
34 In der Absicht, einen Ersatz für den Gottesbegriff der jüdisch-christlichen Tradition anzubieten, gleicht Döblin Ernst Haeckel und dessen „monistischer Religion“; HAECKEL 1961: 436-440; vgl. CORNELSEN 1999: 222.

35 Zu den Eigenschaften Gottes vgl. HÖFER \& RAHNER 1959: 734-735.
} 
Religion als Institution geht, da sie, so Döblin, sowohl die menschliche Tätigkeit lähmt, als auch den Menschen eine falsche Sicht der physikalischen Natur anbietet, indem sie Gottesvorstellungen, welche anthropomorphe Züge beinhaltet, und Jenseitsglauben vermittelt. Deshalb, ist das Christentum - und auch das Judentum - nach Döblins Auffassung der zwanziger und der dreißiger Jahre nur nach dessen Erneuerung als „positive" Religion anzusehen. Diese „Erneuerung“ wäre nach seiner Auffassung nur dann möglich, wenn man letztlich die Unbrauchbarkeit des Gottesbegriffs im „naturalistischen Zeitalter“ erkennen würde. Wie man weiß, findet später eine Art „Erneuerung“ statt, und zwar nicht des Christentums, sondern von Döblins „beseeltem“ Atheismus im Rückgriff auf Jenseitsglauben und Gottesvorstellungen, als Döblin die umgekehrte Position formuliert, sich zum Katholizismus 1941 bekehrt, und fortan weder Gottesoffenbarung noch Gottes Attribute - etwa Person, Gnade, Barmherzigkeit, Vorsehung, Wille und Gerechtigkeit - ablehnt, wie dies in den zwanziger und dreißiger Jahren des 20. Jahrhunderts der Fall ist.

\section{Literaturverzeichnis}

CORNELSEN, Elcio. Gott oder Natur? „Metaphysische Unterströmungen“ im Werk Alfred Döblins. (Diss.), Berlin, FUB, 1999.

Dahnke, Hans-Dietisch. / Отто, Regine (Hrsg.) Goethe Handbuch. Personen. Sachen. Begriffe, 4.Bd. 2, Stuttgart Weimar, Metzer, 1998.

DöBlin, Alfred: „Buddho und die Natur“ (1921). In: Die neue Rundschan 32, 1921, 1192-1200.

DöBlin, Alfred. Die drei Sprünge des Wang-lun. Chinesischer Roman, 1.Aufl., München, dtv, 1989.

DÖBLIN, Alfred: „Der Geist des naturalistischen Zeitalters“ (1924). In: Die neue Rundschau 35, 1924, 1275-1293.

DöBLIn, Alfred: „An die Geistlichkeit“ (1919) (Unter Pseudonym Linke Poot). In: Die neue Rundschau 30, 1919, 1270-1277. In: DöBLIN, Alfred. Der deutsche Maskenball, von Linke Poot/Wissen und Verändern!, Olten / Freiburg i.Br., Walter-Verlag, 1972a, 47-55.

DöBlin, Alfred. Das Ich über der Natur, 4.Aufl., Berlin, Fischer, 1928. 


\section{CORNELESEN, E. - Alfred Döblin, Naturphilosoph}

DÖBLIN, Alfred: „Jenseits von Gott“ (1919). In: Erbebung I, 1919, 381-398. In:

DöBLIN, Alfred. Kleine Schriften I, Olten / Freiburg i.Br., Walter-Verlag, $1985,246-261$.

DöBlin, Alfred: „Krieg und Frieden“ (1920). In: Der neue Merkur 4, 1920/21, 193-207. In: DöBLIN, Alfred. Schriften zur Politik und Gesellschaft, Olten / Freiburg i.Br., Walter-Verlag, 1972b, 152-169.

DöBLIN, Alfred: „[Mein Standort]“ (um 1930). In: DöBLIN, Alfred. Schriften zu Leben und Werk, Olten / Freiburg i.Br., Walter-Verlag, 1986, 193-194.

DöBlin, Alfred: „Die Natur und ihre Seelen“ (1922). In: Der neue Merkur 6, 1922a, 5-14.

DöBlin, Alfred. Reise in Polen, 2.Aufl., München, dtv, 1993.

DöBLIN, Alfred: „'Der Tod des Empedokles““ (3.7.1923). In: DöBLIN, Alfred. Kleine Schriften II, Olten / Freiburg i.Br., Walter-Verlag, 1990, 274-278.

DöBLIN, Alfred. Wissen und Verändern! Offener Brief an einen jungen Menschen (1931). In: DöBlin, Alfred. Der deutsche Maskenball von Linke Poot/Wissen und Verändern!, Olten / Freiburg i.Br., Walter-Verlag, 1972c, 127-266.

Dronske, Ulrich. Tödliche Präsens/zen. Über die Philosophie des Literarischen bei Alfred Döblin, Würzburg, Königshausen + Neumann, 1998.

DschuANG Dsi Das Wahre Buch vom südlichen Blütenland, übersetzt vom Richard Wilhelm, 7.Aufl., München, Eugen Diederichs Verlag, 1992.

EgGEBRECHT, Axel. „Berliner Tageblatt (Abendausgabe) vom 1.6.1932.“ In: Schuster, Ingrid / BODE, Ingrid (Hrsg.) Alfred Döblin im Spiegel der zeitgenössischen Kritik, Bern / München, Francke Verlag, 1973, 151-153.

EHRENBERG, Hans, „Eckart 4, 1928, 406-410“. In: SCHUSTER, Ingrid /BODE, Ingrid (Hrsg.) Alfred Döblin im Spiegel der zeitgenössischen Kritik, Bern / München, Francke Verlag, 1973, 199-204.

ELM, Ursula. Literatur als Lebensanschauung. Zum ideengeschichtlichen Hintergrund von Alfred Döblins „Berlin Alexanderplatr", Bielefeld, Aisthesis, 1991.

EMRICH, Wilhelm: „Begriff und Symbolik der ,Urgeschichte’ in der romantischen Dichtung“. In: Deutsche Vierteljabrsschrift für Literaturwissenschaft und Geistesgeschichte 20, 1942, 273-304.

GoETHE, Johann Wolfgang von. „Zur Farbenlehre.“ In: GOETHE, Johann Wolfgang von. Goethes Werk, 1.Bd., 2.Abt., Weimar, Böhlau, 1890. 
GoETHE, Johann Wolfgang von. „Zur Morphologie.“ In: GoETHE, Johann Wolfgang von. Goethes Werk, 6.Bd., 2.Abt., Weimar, Böhlau, 1891.

Grimm, Jakob / Grimm, Wilhelm. Deutsches Wörterbuch, 11.Bd., 2.Abt., bearbeitet von Karl Euling, Leipzig, S. Hirzel Verlag, 1936.

Grunwald, Max. Spinoza in Deutschland, Neuausgabe, Darmstadt, Scientia Verlag, 1986.

HAECKEL, Ernst. Die Welträtsel. Gemeinverständliche Studien über monistische Philosophie, Berlin, Akademie-Verlag, 1961.

HARDENBERG, Friedirch von. Fragmente. Dresden, Jess, 1929a.

HARDENBERG, Friedirch von. „Heinrich von Ofterdingen.“ In: HardenberG, Friedirch von. Novalis Schriften, 1.Bd., hg. v. Paul Kluckhohn, Leipzig, Jess, 1929b, 97-260.

HARDENBERG, Friedirch von: „Der sterbende Genius“. In: HARDENBERG, Friedirch von. Novalis Schriften, 1.Bd., hg. v. Paul Kluckhohn, Leipzig, Jess, 1929c, 352.

HASLINGER, Josef. Die Ästhetik des Novalis, Königstein/Ts., Hain-Verlag, 1981.

HeNEL, Heinrich: „Typus und Urphänomen in Goethes Naturlehre“. In: HeNEL, Heinrich. Goethezeit, Memmingen, Insel, 1980, 158-181 bzw. 364-371.

HÖFER, Josef / RAHNER, Karl (Hrsg.) Lexikon für Theologie und Kirche, 1.-10.Bd., 2.Aufl., Freiburg i.Br., Herder, 1957-1965.

HÖLDERLIN, Friedrich: „Emilie vor ihrem Brauttag“. In: HöLDERLIN, Friedrich. Sämtliche Werke, 1.Bd., Stuttgart, Cotta, 1946a, 277-297.

HÖLDERLIN, Friedrich: „Hymne an die Schönheit“ [Erste Fassung]. In: HöLDERLIN, Friedrich. Sämtliche Werke, 1.Bd., Stuttgart, Cotta, 1946b, 149-151.

HÖLDERLIN, Friedrich. Hyperion oder Der Eremit in Griechenland. In: HÖLDERLIN, Friedrich. Sämtliche Werke, 3.Bd., Stuttgart, Cotta, 1946c, $1-166$.

HÖLDERLIN, Friedrich. Hyperion, [Die metrische Fassung]. In: HölDERLIN, Friedrich. Sämtliche Werke, 3.Bd., Stuttgart, Cotta, 1946d, 186-198.

HÖlDERLIN, Friedrich: „Zu Jakobis Briefen über die Lehre des Spinoza“. In: HöldERLIN, Friedrich. Sämtliche Werke, 4.Bd., Stuttgart, Cotta, 1961a, 207-210. 


\section{CORNELESEN, E. - Alfred Döblin, Naturphilosoph}

Hölderlin, Friedrich: „Kanton Schweiz. An meinen Lieben Hiller“. In: HöLDERLIN, Friedrich. Sämtliche Werke, 1.Bd., Stuttgart, Cotta, 1946e, 143-145.

HÖLDERLIN, Friedrich: „Die Unsterblichkeit der Seele“. In: HÖLDERLIN, Friedrich. Sämtliche Werke, 1.Bd., Stuttgart, Cotta, 1946f, 31-35.

HÖLDERLIN, Friedrich: „Wenn aus der Ferne...“ In: HÖLDERLIN, Friedrich. Sämtliche Werke, 2.Bd., Stuttgart, Cotta, 1946g, 262-263.

HÖLDERLIN, Friedrich: „Das Werden im Vergehen“. In: HÖLDERLIN, Friedrich. Sämtliche Werke, 4.Bd., Stuttgart, Cotta, 1961b, 282-287.

KLEIN, Otto. Das Thema Gewalt im Werk Alfred Döblins. Ästhetische, ethische und religiöse Sichtweise, Hamburg, Verlag Dr. Kovac, 1995.

KüNG, Hans. Existiert Gott? Antwort auf die Gottesfrage der Neuzeit, 3.Aufl, München/Zürich, Piper, 1995.

KunZmann, Peter. (u.a.) (Hrsg.) dtv-Atlas Philosophie, 7. überarb. u. erw. Aufl., München, dtv, 1998.

LAOTSE Tao te king. Das Buch vom Sinn und Leben, übersetzt und mit einem

Kommentar von Richard Wilhelm, 7.Aufl., München, Eugen Diederichs Verlag, 1993.

LiÄ DSI Das wahre Buch vom quellenden Urgrund, aus dem Chinesischen übertragen und erläutert von Richard Wilhelm, 4.Aufl., München, Eugen Diederichs Verlag, 1992.

Mauthner, Fritz. Der Atheismus und seine Geschichte im Abendlande, 4.Bd., Hildesheim, Olms, 1963.

MuschG, Walter: „Nachwort des Herausgebers“. In: DöBLIN, Alfred. Die Drei Sprünge des Wang-lun. Chinesischer Roman, München, dtv, 1989a, 481-502.

NeubAuER, John: „Das Verständnis der Naturwissenschaften bei Novalis und Goethe“. In: Uerlings, Herbert. (Hrsg.) Novalis und die Wissenschaft, Tübingen, Niemeyer, 1997, 49-63.

PIZER, John: „Goethe’s ,Urphänomen’ and Benjamin's ,Ursprung’: A Reconsideration“. In: Seminar 25, 1989, 205-222.

RoDer, Florian. Novalis. Die Verwandlung des Menschen. Leben und Werk Friedrich von Hardenbergs, Stuttgart, Urachhaus, 1992.

SCHMIDT, Heinrich. Philosophisches Wörterbuch, 22.Aufl., Stuttgart, Kröner, 1991. 
SCHRÖTER, Klaus. Alfred Döblin, Reinbek bei Hamburg, Rowohlt, 1988.

StÖRIG, Hans-Joachim. J. Kleine Weltgeschichte der Philosophie, erw. Neuausgabe, Frankfurt a.M., Kohlhammer, 1995.

WanNING, Berbeli. Novalis zur Einfübrung, Hamburg, Junius, 1996.

Weyembergh-Boussart, Monique von. Alfred Döblin. Seine Religiosität in Persönlichkeit und Werk, Bonn, Bouvier, 1970.

ZAHN, Manfred.: „Gott und die große Künstlerin Natur. Von Giordano Bruno zu Immanuel Kant“. In: SCHUBERT, Venanz. (Hrsg.) Was lehrt uns die Natur? Die Natur in den Künsten und Wissenschaften, St. Ottilien, EOS-Verlag, 1989, 61-134. 